\title{
Corporate Finance and the Monetary Transmission Mechanism*
}

\author{
Patrick Bolton $^{\dagger} \quad$ Xavier Freixas ${ }^{\ddagger}$
}

June 2000

\begin{abstract}
This paper analyzes the transmission mechanisms of monetary policy in a general equilibrium model of securities markets and banking with asymmetric information. Banks' optimal asset/liability policy is such that in equilibrium capital adequacy constraints are always binding. Asymmetric information about banks' net worth adds a cost to outside equity capital, which limits the extent to which banks can relax their capital constraint. In this context monetary policy does not affect bank lending through changes in bank liquidity. Rather, it has the effect of changing the aggregate composition of financing by firms. The model also produces multiple equilibria, one of which displays all the features of a "credit crunch". Thus, monetary policy can also have large effects when it induces a shift from one equilibrium to the other.
\end{abstract}

*We thank Ben Bernanke, Tryphon Kollintzas, Marcus Miller and Xavier Vives for helpful comments. We have also received comments from seminar participants at the IMF, Hebrew University of Jerusalem, Universitat Pompeu Fabra, H.E.C Paris, Stockholm School of Economics and the CEPR workshop on Banking and Financial Markets. Support from DGICYT grant no. PB98-1057 is gratefully acknowledged.

†Princeton University, CEPR and NBER

¥Universitat Pompeu Fabra and CEPR 


\section{Introduction}

This paper is concerned with the general question of the monetary transmission mechanisms in the financial sector, that is the banking sector and securities markets. Specifically, it analyzes the effects of open market operations on bank lending and securities market equilibrium. By building on recent advances in the microeconomics of banking it provides the underpinnings of the "credit view" of monetary policy which relies on some exogenously given degree of substitution between bank lending and bond financing.

A key question with respect to the effects of monetary policy is whether banks are capital constrained or not. This paper takes as a starting point the view that banks capital requirement constraints are binding.

Given the importance of this constraint, it is essential to understand what limits the availability of capital for banks, or in other words, what the cost of outside capital are for banks. Our perspective in this paper is that these costs are primarily information dilution costs à la Myers and Majluf (1984). That is, when a bank decides to raise additional equity through a seasoned offer, the market tends to undervalue the issue for the better banks. But since it is the better banks that drive the decision whether to raise equity, the overall effect on all banks equity issues (whether good or bad) is to reduce the amount of equity raised relative to the full information optimum. Thus, because of information asymmetries about the fundamental value of the bank, an endogenous cost of equity is generated, and by implication an endogenous cost of bank lending. Hence, banks' equity base (and internally generated funds) are a key variable in determining the total amount of bank credit.

An important consequence of this endogenous cost of equity is that multiple equilibria may coexist for given identical underlying parameters of the economy. In one equilibrium the endogenous cost of capital (generated by self fulfilling market beliefs) is high while in the other it is low. The former has all the main features of a "credit crunch", namely that bank lending is limited by a lower endogenous stock of bank capital, a lower volume of credit and high equilibrium bank spreads. On the other hand, the latter equilibrium has a high stock of bank capital, a high volume of credit and lower equilibrium bank spreads.

Another way of thinking about this multiplicity of equilibria is in terms of hysteresis in market beliefs about underlying bank values. Starting from a low level of equilibrium bank capital, any equity issue is likely to be inter- 
preted by the market as a bad signal about the issuing banks value (resulting in a reduction in the market price of the bank equity), thus inhibiting new equity issues. Vice-versa, in a situation where most banks are expanding their capital base, a failure to expand will be interpreted as a negative signal. This is the source of multiplicity of equilibria in our model.

In light of this potential multiplicity of equilibria, an important question for monetary policy transmission is the extent to which it induces a switch from one equilibrium to another. In our model there is a potential amplifying effect of open market operations. Any tightening in monetary policy through an increase in Treasury yields, has the effect in our model of reducing equilibrium bank spreads and thus to reduce banks' incentives to raise capital. In particular, it is possible that tightening monetary policy may induce a switch to a "credit crunch" equilibrium.

Other effects of monetary policy that our analysis highlights are related to the financial composition of the corporate sector between securities issues and bank credit. Recent empirical work suggests that one important effect of monetary policy is to change firms' financial structure decisions, corporations substituting bank lending for commercial paper issues. A common explanation for these changes is that when bank capital is tight, firms turn to the securities market to raise funds (see Kashyap and Stein (1994) and Gertler and Gilchrist (1994)).

We are able to address these issues because our model allows for both a securities market and a banking sector and because it lets firms determine endogenously their capital structure. The corporate financing side of the model here builds on the analysis in our companion paper (Bolton and Freixas, 2000). While our model goes substantially beyond existing partial equilibrium models of the "credit channel" it is not a fully general equilibrium model to the extent that it abstracts from consumption, real cash balances, and aggregate demand effects relating to price stickiness, which have been the main focus of existing macroeconomic analyses of the monetary transmission mechanism.

What distinguishes bank debt from corporate bond financing in our model is the flexibility of the two modes of financing: bank debt is easier to restructure but because bank loans are in short supply, there is an endogenous cost of flexibility. What makes bank loans expensive is the existence of a capital requirement regulation as well as the fact that issuing new equity is costly. This is the source behind the existence of an equilibrium spread between bank loans and bonds. 
Firms with higher variance in cash-flows are willing to pay this intermediation cost because they have a greater benefit of flexibility. This is where monetary policy affects the composition of financing: by affecting the equilibrium bank spread it induces the marginal firms to switch between intermediated and market financing. Bank debt is an imperfect substitute for bonds and therefore the effects of monetary policy on investment cannot be determined entirely by looking only at the effects on aggregate debt as the "money view" prescribes. One is, thus, inevitably led in the direction of a more complex view of the monetary transmission mechanism.

There are several recent papers dealing with the 'credit channel' of monetary policy that are related to ours. The three most closely related ones are Gorton and Winton (1999), Van den Heuvel (1999) and Schneider (1998). The first two papers focus on banks' capital adequacy constraints and the macroeconomic effects of changes in bank lending induced by changes in banks' equity base ${ }^{1}$. Bank capital is costly in Gorton and Winton because bank equity is risky and therefore requires both a risk and liquidity premium. Capital adequacy constraints impose a cost on banks whenever investors' optimal portfolio is less heavily weighted towards bank equity than is required by regulations. This is most likely to occur in recessions. Accordingly the amplification effects of monetary policy are greatest at the onset of a recession, when higher interest rates affect aggregate investment both directly and indirectly through a reduction in bank lending capacity. In Van den Heuvel the cost of bank equity is exogenous. Banks are not allowed to raise new equity, but they can increase their capital stock through retained earnings. The amplification effects of monetary policy then work through their effects on retained earnings. While Van den Heuvel's microeconomic model of banking is more rudimentary than that of Gorton and Winton his dynamic macroeconomic analysis goes considerably further, exploring lagged effects of changes in interest rates. Similarly, Schneider provides an extensive dynamic macroeconomic analysis, which relies on a combination of liquidity and bank capital effects.

Neither of these models, however, allows for other sources of financing besides bank lending and therefore cannot explore composition effects of monetary policy ${ }^{2}$. Nor do these models allow for multiple equilibria and

\footnotetext{
${ }^{1}$ See also Thakor (1996), which assumes an exogenous cost of bank equity and explores the implications of raising banks' funding costs by requiring them to hold more costly equity.

${ }^{2}$ From a conceptual point of view, a common weakness of models which allow for only
} 
the possibility of what we describe as a "credit crunch" equilibrium, where bank lending is constrained by investors' excessive pessimism about banks' underlying asset values.

Another set of related papers deals with effects of monetary policy on bank lending through changes in reserve requirements. Thus, Lucas and McDonald (1992) and Stein (1998) explore the extent to which non-deposit liabilities are a perfect substitute for deposit liabilities (subject to reserve requirements) when banks have private information about their net worth. They show that when certificates of deposit (CDs) are risky then banks are unable to perfectly substitute CDs for deposits, so that bank lending may be partially controlled by monetary authorities through changes in reserve requirements. Neither paper considers the effects of capital adequacy constraints, or the general equilibrium effects of monetary policy on the entire financial sector.

Finally, a third set of related papers is Holmstrom and Tirole (1997), Repullo and Suarez (1998) and Bolton and Freixas (2000)). These three papers characterize the equilibrium co-existence of bank lending and direct financing through securities issues. As in this paper bank lending is modelled as more flexible but more costly. All three papers assume effectively exogenous intermediation costs and do not analyse the effects of monetary policy on aggregate investment.

The paper is organized as follows: section 2 is devoted to the description of the model while section 3 deals with banks lending and their asset/liability structure. Section 4 characterizes the general equilibrium when banks' equity is fixed and Section 5 considers comparative statics and the effect of monetary policy in that case. Section 6 endogenizes the supply of bank equity and shows how a "credit crunch" equilibrium may obtain. Finally Section 7 concludes. The proofs of most results are given in an appendix.

bank lending without any other direct source of funding for firms is that banks in these models look essentially like non-financial firms, the only difference being that they are subject to capital adequacy requirements imposed in exchange of deposit insurance. 


\section{The model}

\subsection{Firms' investment projects and financial options}

Each firm has one project requiring an investment outlay $I>1$ at date $t=0$ and yielding two possible returns at dates $t=1$ and $t=2: \pi_{H}$ or 0 . The project can be liquidated at $t=1$ at a resale value $0<A<\pi_{H}$. Firms' owner-managers invest $W<I$ in the firm and must raise $I-W=1$ from outside. Firms differ in the probabilities $p_{1}$ and $p_{2}$ of obtaining high cash flow realizations in respectively periods 1 and 2 . We assume that $p_{1}$ is uniformly distributed on the interval $[0,1]$, and that the value of $p_{2}$ is drawn independently from $\{0,1\}$.

We take $p_{1}$ to be publicly observable, but $p_{2} \in\{0,1\}$ to be private information to the firm at $t=0$. The probability $p_{1}$ can be thought of as a credit rating. We refer to a firm with date $t=2$ cash-flow of $\pi_{H}$ as a type $H$-firm and to a firm with date two zero cash-flows as a type $L$-firm. The type of the firm is private information to the entrepreneur at time $t=0$. It is only revealed at $t=1$ to a bank who has lent to the firm at $t=0$, and it becomes public only at $t=2$. At date $t=0$, creditors' prior beliefs about the value of $p_{2}$ are that $p_{2}=1$ with probability $\nu\left(\right.$ and $p_{2}=0$ with probability $1-\nu$ ) so that $E\left[p_{2}\right]=\nu$.

The least risky firms (with a high $p_{1}$ ) are obviously assumed to have positive net present value projects:

$$
\mathrm{A} 0: \pi_{H}+\nu \pi_{H}>I
$$

Also, we shall assume that firms with a low second period cash-flow have a negative net present value for all values of $p_{1}$.

$$
\text { A1: } \pi_{H}<1 \text {, }
$$

This assumption rules out signalling equilibria where the firm's choice of capital structure may reveal its type. Indeed, under assumption A1, a firm with a low second period cash-flow always wants to mimic a good firm for otherwise it would never obtain any funding. We focus on the case where continuation is, on average, preferred to liquidation, that is:

$$
\nu \pi_{H}>A
$$


Firms can choose to finance their project by either issuing bonds or by means of a bank loan. To keep the corporate financing side of the model to its bare essentials, we do not allow firms to issue equity or to combine bonds and bank debt (however, these options are examined in Bolton and Freixas (2000)). The main distinguishing features of these two instruments are the following:

1. bond financing: a bond issue specifies a repayment schedule to bond holders of $R(\mathbf{p})=\left\{R_{1}\left(p_{1}\right), R_{2}\left(p_{2}\right)\right\}$, where $R_{1}\left(p_{1}\right)$ is the date $t=1$, and $R_{2}\left(p_{1}\right)$ the date $t=2$ repayment. If the firm is unable to meet its repayments at date $t=1$ the firm is declared bankrupt and is liquidated. Restructuring of debt is not possible because of the wide dispersion of ownership of corporate bonds (see e.g. Bolton and Scharfstein (1996)). Firms are allowed to roll over their bonds by offering new issues at date $t=1$.

2. bank debt: a bank loan specifies a repayment schedule $\widehat{R}(\mathbf{p})=\left\{\widehat{R}_{1}\left(p_{1}\right)\right.$, $\left.\widehat{R}_{2}\left(p_{2}\right)\right\}$. If the firm defaults at date $t=1$ the bank is able to observe the type of firm (through monitoring) and decides whether to liquidate or let the firm continue. If it lets the firm continue it appropriates all last period returns through a debt/equity swap. The bank lets the firm continue if and only if second period cash-flow is $\pi_{H}$.

Because the asymmetric information concerns only cash-flows at time $t=$ 2 , it is intuitive that both for bond financing and for bank debt the optimal contracts are characterized by a maximum repayment in the first period: $\widehat{R}_{1}\left(p_{1}\right)=R_{1}\left(p_{1}\right)=\pi_{H}$. Thus we will restrict the contracts to the efficient ones and consider that the only endogenous characteristics of contracts are time $t=2$ repayments.

As in Bolton and Freixas (2000), the choice of funding is determined by $\mathrm{H}$ firms, with $L$-firms imitating them. In equilibrium, firms will be segmented by risk classes in their choice of funding, with all firms with $p_{1} \in\left(p_{1}^{*}, 1\right]$ choosing bond financing and all firms with $p_{1} \in\left[0, p_{1}^{*}\right]$ preferring a bank ${ }^{l o a n}{ }^{3}$. Bond financing dominates for low risk firms (with a high $p_{1}$ ) because these firms are less likely to fail at date $t=1$ and therefore have less of a need for the costly debt restructuring services provided by banks. These services

\footnotetext{
${ }^{3}$ We avoid the complexities of the riskier firms issuing junk bonds, even if this may arise for some constellation of parameters
} 
are costly because banks themselves need to raise funds to be able to lend to firms. In Bolton and Freixas (2000) these fund raising costs were specified exogenously. In contrast, here these costs are partially endogenized.

Having described the demand side for capital by firms we now turn to a description of the supply side.

\subsection{Households}

There is a continuum of risk-neutral households in our economy represented by the unit interval $[0,1]$. We shall only be concerned with households' savings and investment decisions and abstract from their consumption behavior. Each household has one unit of savings of which a fraction $(1-d)$ is allocated in financial markets (corporate or government bonds) and a fraction is used for transaction purposes and can be held either as cash or as bank deposit account. The supply of deposits is denoted by $D\left(R_{D}\right)$ (with $0 \leq D\left(R_{D}\right) \leq d<1$ ), where $R_{D}$ is the remuneration of deposits. We do not allow for perfect substitutability between deposit accounts and financial assets partly for simplicity and partly to reflect the fact that bank deposits mostly serve transactions needs and are not pure investment instruments. However, we let depositors react to the opportunity cost of holding cash by restructuring their holdings of cash and bank deposits.

For simplicity we take the supply of deposits function $D\left(R_{D}\right)$ to be piecewise linear and equal to

$$
D\left(R_{D}\right)= \begin{cases}0 & \text { for } R_{D}<1 \\ b\left(R_{D}-1\right) & \text { for } 1 \leq R_{D} \leq 1+\frac{d}{b} \\ d & \text { for } R_{D}>1+\frac{d}{b}\end{cases}
$$

\subsection{Banks}

Banks, as firms, are run by self-interested managers, who have invested their personal wealth $w$ in the bank. They can operate on a small scale by leveraging only their own capital $w$, with (insured) deposits $D$ and/or a bond issue $B_{b}$, so as to fund a total amount of loans $w+D+B_{b}$. By limiting their capital base to $w$ their lending capacity will be constrained by capital 
adequacy requirements ${ }^{4}$ :

$$
\frac{w}{w+D+B_{b}} \geq \kappa>0
$$

The unit cost of deposits is given by $\left(c+R_{D}\right)$, where $c$ denotes a real cost of retail banking and $R_{D}$ a (gross) interest cost. We assume that banks are local monopolies that set their deposit rate $R_{D}$. Banks in our model never fail and the bonds they issue are safe ${ }^{5}$. Therefore, bank bonds have the same interest cost as government bonds: $R_{G}$. Our model is thus consistent with the traditional Monty and Klein view that banks compete for wholesale funds but are monopolies for local funds.

Banks are only able to expand lending beyond the threshold $\frac{w}{\kappa}$ by raising more equity - E. However, when they raise outside equity they may face informational dilution costs. Outside equity investors, having less information about the profitability of bank loans will tend to misprice banks' equity issues. In particular, they will underprice equity issues of the most profitable banks. We assume that banks choose an amount of equity to issue within the interval $[0, \bar{E}]$, where $\bar{E}<\infty^{6}$.

To capture banks' dilution costs of capital in a simple and stark way we shall suppose that bank managers are more or less able at screening good loans. We shall assume that good bank managers (or type $H$-banks) can perfectly discriminate $H$-firms from $L$-firms, while bad bank managers (or $L$-banks) cannot distinguish them at all. However, although $L$-banks do not know the type of the firm at date $t=0$ they still learn the firm's type at date $t=1$. Therefore, at that point they can make an efficient liquidation/continuation decision.

\footnotetext{
${ }^{4}$ The BIS capital adequacy rules in our highly simplified model are that $\kappa=0.08$ for standard unsecured loans.

${ }^{5}$ Banks would not go bankrupt if the minimum required capital base is large enough and if their loan portfolio is sufficiently diversified. Since we are assuming that firms' cash-flows are independently distributed banks' loan investments can be perfectly diversified. Thus, to guarantee that banks do not fail it suffices that $\kappa$ is large enough. This is undoubtedly a strong simplifying assumption, which we would like to relax in future work.

${ }^{6}$ We justify the existence of an upper bound on $E$ by the following potential incentive problem between bank mangers and bank shareholders: if the bank raises an amount superior to $\bar{E}$ then bank managers may have an incentive to abscond with the money or use it to increase their private benefits. Indeed, the larger is $E$ the greater the private benefits relative to the cost in terms of loss of reputation.
} 
Banks' outside investors do not know the bank's type; all they know is that there is a mass $M$ of $H$-banks and $m$ of $L$-banks. So, their prior belief about a bank's type is that they face an $L$-bank with probability $m /(M+m)$ and an $H$-bank with probability $M /(M+m)$. We normalize the mass of respectively $H$ - and $L$-banks so that $M+m=1$. This informational asymmetry about bank type gives rise to mispricing of each bank type's equity. It is the main source of costs of bank capital in our model.

A bank manager seeks to maximize bank profits and also to raise the bank's share price as much as possible. The reason why a bank manager cares about share price is that he may want to sell his stake in the bank before the returns of the bank's loans are fully realized and known.

We model these objectives by assuming that bank managers may need to liquidate their stake in the bank at date $t=1$ with probability $\lambda \in(0,1)$. Denoting by $q$ the share price of the bank and by $\Pi_{2}$ the bank's accumulated profit up to period $t=2$, the bank manager's objective is then to maximize ${ }^{7}$

$$
\max \left[q, \lambda q+(1-\lambda) \Pi_{2}\right] .
$$

If the manager is running an $L$-bank and he knows that $\Pi_{2}<q$ (based on his private information) then he will always sell his stake at date $t=1$ and he will only care about the bank's share price. If, on the other hand, he is running an $H$-bank such that $\Pi_{2}>q$ then he will seek to maximize $\lambda q+(1-\lambda) \Pi_{2}$.

Having determined banks' objectives, their investment opportunities and their sources of funds we now can turn to an analysis of their optimal lending policy and asset/liability structure given fixed market terms.

Before doing so we briefly summarize the sequencing of moves and events, and also recall the underlying information structure.

\section{$2.4 \quad$ Timing}

1. At date $t=0$ banks begin by quoting lending terms $\widehat{R}_{2}\left(p_{1}\right)$ to firms and (gross) interest rates on deposit accounts $R_{D}$. Simultaneously,

\footnotetext{
${ }^{7}$ Note that this objective function is similar to that considered by Myers and Majluf (1984). However, it is not vulnerable to the criticisms voiced against their specification (see e.g. Dybvig and Zender (1989)). Note also that bank managers' private benefits are not explicitly modeled. The reason is that banks never fail in our model so that the issue of bank managers' objectives regarding liquidation or continuation of the bank never arises explicitly.
} 
the government and firms issuing bonds quote their respective terms, $R_{G}$ and $R_{2}\left(p_{1}\right)$.

- Those firms who prefer bank lending then apply for a loan. If an $L$-firm applies to an $H$-bank its application is turned down. An $L$-firm whose application has been denied can apply to another bank until it finds a bank that is willing to lend ${ }^{8}$.

- In a second stage, banks decide on their asset/liability portfolio. In particular, they decide what proportion of their funds to invest in new loans and what proportion in government or corporate bonds.

- Finally, banks choose the amount of new equity they want to issue, E.

- Next, households determine the fraction of their endowment they want to hold as cash $\left[d-D\left(R_{D}\right)\right]$ or deposits $D\left(R_{D}\right)$, and they decide how they want to allocate their investments $(1-d)$ in the financial market:either in government bonds $G$, corporate bonds $B_{c}$, bank bonds $B_{b}$, or bank equity $E$.

- Once all the household savings have been allocated to the government, firms and banks, these funds are invested in projects.

2. At date $t=1$ firms' first period returns are realized. Firms repay their first-period debts if they can. Otherwise, they are liquidated (when they are bond financed) or reorganized. ${ }^{9}$

At this date bank managers also have the option to sell their equity stake in the secondary market.

3. At date $t=2$ all remaining debts as well as dividends are paid and households consume their net after tax income.

\footnotetext{
${ }^{8}$ We assume that a firm that has been denied credit is indistinguishable from a first applicant. Also, an applicant that has been denied credit cannot communicate that information to others.

${ }^{9}$ When a firm faces reorganization, we assume it hands over all its assets to the bank that will choose the best course of action, liquidation for L-firms and continuation for $\mathrm{H}$-firms. In the former case the bank obtains $A$ and in the latter it obtains $\pi_{H}$.
} 


\subsection{The Government sector}

The only aspect of government we focus on in this paper is deficit financing through government bonds. To focus on the direct impact of government bond issues on the financial sector we abstract from possible feed-back effects on firms' profitability of government spending. Thus, for our purposes the only relevant part of government is the total amount of debt it decides to issue - $G$ - and the equilibrium gross rate of return on government bonds - $R_{G}$. Government debt is entirely reimbursed at date $t=2$ out of the revenues generated by a tax on date $t=2$ income. The size of the debt determines the extent of crowding out of private investment and, through $R_{G}$, the composition of private debt and bank assets.

\section{Bank Lending and Optimal Asset-Liability Structure}

We consider optimal lending and asset-liability management from the perspective of $H$-banks, who know that their actions are mimicked by $L$-banks. The reason why $L$-banks always mimic $H$-banks is the same as with firms: $L$-banks are negative NPV institutions, which would not get any outside equity funding once they are identified. Below, we give sufficient conditions guaranteeing that $L$-banks are not profitable ${ }^{10}$.

An $H$-bank contemplating an equity issue faces the following trade-off. If it issues equity it can increase lending and thus raise profits, but since it's equity is undervalued in the financial market the bank's manager does not appropriate the entire increase in profits. Depending on the profitability of loans and the extent of the undervaluation of equity the $H$-bank may or may not decide to relax it's lending constraint by issuing more equity. Thus, to determine an $H$-bank's choice we need to specify the profitability of loans and the extent of dilution.

\footnotetext{
${ }^{10}$ The reason why we restrict attention to situations where $L$-banks always mimick $H$ banks is to keep the analysis as tractable as possible. It should be clear that even if equilibria where $H$-banks can separate themselves from $L$-banks may exist for other parameter values these equilibria would also have positive intermediation costs and therefore would be qualitatively similar to the pooling equilibria characterized in the body of the paper.
} 


\subsection{Optimal Lending Policy}

In equilibrium the lending terms that $H$ or $L$-banks offer are the same. Otherwise any deviation by an $L$-bank would reveal its type and hit its share price. We give sufficient conditions below guaranteeing that the cost of a fall in share price outweighs any benefit to $L$-banks from undercutting $H$-banks' terms in the loan market.

The optimal loan contract that $H$-banks offer firms are such that date $t=$ 1 repayments are equal to first period (expected) revenues, $p_{1} \pi_{H} \equiv \bar{\pi}$. Indeed, such a contract minimizes firms' informational dilution costs. By assumption A1 such a repayment alone would not cover the date $t=0$ investment costs. Therefore, a second period repayment, $\widehat{R}_{2}\left(p_{1}\right)$ is also required ${ }^{11}$.

Given these lending terms, $H$-banks get a higher return per loan than $L$-banks since $H$-banks perfectly screen $H$-firms from $L$-firms, while $L$-banks cannot distinguish between the two types of firms.

If we denote by $\widehat{\nu}$ the probability that an $L$-bank lends to an $H$-firm ${ }^{12}$ and by $\left(\rho_{H}, \rho_{L}\right)$ the expected net excess return per loan over the interest on government bonds of respectively $H$ and $L$-banks, then given equal lending terms we have:

$$
\begin{aligned}
\rho_{H} & =\bar{\pi}\left(p_{1}\right)+\left(1-p_{1}\right) \pi_{H}+p_{1} \widehat{R}_{2}\left(p_{1}\right)-R_{G} \text { and } \\
\rho_{L} & =\bar{\pi}\left(p_{1}\right)+\left(1-p_{1}\right) \widehat{\nu} \pi_{H}+p_{1} \widehat{\nu} \widehat{R}_{2}\left(p_{1}\right)+(1-\widehat{\nu}) A-R_{G}
\end{aligned}
$$

The returns of $L$-banks can thus be written as a function of $H$-banks' returns:

$$
\rho_{L}=(1-\widehat{\nu})\left(\bar{\pi}\left(p_{1}\right)+A-R_{G}\right)+\widehat{\nu} \rho_{H}
$$

Now, given these lending terms and given rates on respectively deposits and government bonds of $R_{D}$ and $R_{G}$, an $H$-bank chooses its optimal mix of loans $L$, government bond holdings $G_{b}$, bank bond issues $B_{b}$, and deposits $D\left(R_{D}\right)$, to maximize expected profits subject to capital adequacy constraints.

Because by assumption the expected rates on bank bond issues and government bond holdings are the same, we are only able to determine the net

\footnotetext{
${ }^{11}$ See Bolton and Freixas (2000) for a detailed derivation of the optimal bank loan contract.

${ }^{12}$ In equilibrium, we have $\widehat{\nu} \leq \nu$ since some $H$-firms obtain funding from $H$-banks, while an $L$-firm can only obtain funding from an $L$-bank.
} 
amount of bonds (positive or negative) the bank holds, $G_{b}-B_{b}$.

$$
\left\{\begin{array}{l}
\max _{\left(L, G_{b}, B_{b}, R_{D}\right)}\left\{L\left(R_{G}+\rho_{H}\right)+\left(G_{b}-B_{b}\right) R_{G}-D\left(R_{D}\right)\left(R_{D}+c\right)\right\} \\
\text { subject to: } \\
L+G_{b}=D\left(R_{D}\right)+w+E+B_{b} \quad(A L) \\
L \leq \frac{1}{\kappa}(w+E)
\end{array}\right.
$$

It is easy to see from this program that the capital adequacy constraint is always binding if $\rho_{H}>0$. Indeed, if the excess return on bank lending is strictly positive, an $H$-bank can always make a profit by raising an extra dollar by selling bonds and investing it in a bank loan. It is optimal for the bank to raise funds through deposits up to the point where the marginal cost of deposits $2 R_{D}-1+c$ equals the cost of bonds $R_{G}$.

If, on the other hand, $\rho_{H}<0$, then it is best for the bank not to lend at all to firms and to invest only in the market.

We summarize these observations in the lemma below.

Lemma 1: For $R_{G}$ in the interval $\left(1+c, 1+c+2 \frac{d}{b}\right)$, the optimal amount of deposit funding is $D\left(R_{D}\right)=\frac{b}{2}\left(R_{G}-(1+c)\right)$. The optimal amount of bank lending is $L=\frac{(w+E)}{\kappa}$ if $\rho_{H}>0$ and $L=0$ if $\rho_{H}<0$.

This lemma is fundamental to our whole analysis of the monetary transmission mechanism that follows. It highlights that banks' optimal lending policy and asset/liability structure is such that their capital base is always a binding constraint on their lending capacity. In other words, when bank spreads are positive banks can only increase lending by increasing their capital base. Thus, it becomes essential to consider how banks' capital base is determined.

An important implication of this lemma is that monetary policy cannot affect bank lending by changing bank reserves in our model. In other words, the classical bank lending channel of monetary policy is absent. As has already been noted by Romer and Romer (1990), when banks can perfectly substitute non reservable liabilities for reservable ones, as in our model, the 
bank lending channel can no longer be a transmission mechanism for monetary policy. Bond issues could, of course, become imperfect substitutes for insured deposits if there was a risk of default as Stein (1998) has noted. However, this imperfect substitutability of risky bonds for safe deposits is only a necessary condition for the presence of a bank lending channel. It is not sufficient if capital adequacy constraints remain binding. Indeed, in our model, reserve requirements combined with an imperfect substitutability between bonds and insured deposits would simply raise the bank's overall cost of funds. But as long as spreads remain sufficiently high, banks would continue to raise funds up to the point where the capital constraint binds. Thus, when the central bank changes reserve requirements on deposits, the only effect on banks is on profitability. It cannot affect bank lending if the capital constraint remains binding. Of course, profitability eventually or indirectly affects the availability of capital, so that there may be an indirect or lagged effect as in Van den Heuvel (1999). These points are made more formally in section 5 dealing with comparative statics.

\section{General Equilibrium in the capital market}

In this section we provide sufficient conditions for the existence of equilibrium rates, $R_{D}, R_{G}$, and $\mathbf{R}^{*}\left(\right.$ or $\rho_{H}^{*}, \rho_{L}^{*}$ ), such that:

1. the aggregate demand for bank credit is equal to aggregate supply, where the aggregate demand for bank credit is given by the measure of firms that prefer bank credit to public bond issues.

2. the aggregate demand for bank equity, corporate and government bonds equal the supply of funds to the securities markets,

3. bank demand for deposits equals deposit supply

4. banks do not gain by arbitraging the deposit and Treasury bond markets and,

5. neither $H$-banks nor $L$-banks have an incentive to deviate in either stage 1 , by offering different terms $\mathbf{R} \neq \mathbf{R}^{*}$, or in stage 2 , by making an equity issue $E \neq E\left(\mathbf{R}^{*}\right)$. 
For a given level of equity issues $E$, the equilibrium analysis boils down to solving a system of four equations. We begin with the characterization of this solution and then proceed with the analysis of bank equilibrium equity issues $E$.

We disregard the case $\rho_{H} \leq 0$, since it is compatible with equilibrium only in the trivial case where banks have an excess of funds to finance all projects in the economy and are not capital constrained.

\subsection{Equilibrium in the deposit market}

The supply of deposits function in our model is very simple. Total available deposits are equal to $D\left(R_{D}\right)$ for $R_{D}>1$ and equal to 0 for $R_{D} \leq 1$. We denote the aggregate amount of deposits that results from banks' optimal portfolio decisions by $D\left(R_{D}\left(R_{G}\right)\right)$. From Lemma 1 the equilibrium supply of deposits is then given by:

$$
D\left(R_{D}\left(R_{G}\right)\right)=\left\{\begin{array}{lcc}
0 & \text { for } & R_{G}<1+c \\
\frac{b}{2}\left(R_{G}-(1+c)\right. & \text { for } & 1+c \leq R_{G} \leq 1+c+2 \frac{d}{b} \\
0 & \text { for } & R_{G}>1+c+2 \frac{d}{b}
\end{array}\right.
$$

By implication from the asset-liability equation $(A L)$ we also obtain banks' aggregate demand for bonds:

$$
G_{b}-B_{b}=w+E-L+D\left(R_{D}\left(R_{G}\right)\right) .
$$

\subsection{Equilibrium in the bank credit market}

In equilibrium an $H$-bank equalizes the expected excess return on each loan it grants. Therefore, if the equilibrium excess return $\rho_{H}$ is high a firm with a very low rating $p_{1}$ may see its credit application turned down. The threshold $p_{1}^{B}$ below which firms are rationed is given by the firm for which

$$
p_{1}^{B} \pi_{H}+\pi_{H}=R_{G}+\rho_{H} .
$$

Thus the mass of firms which cannot get any funding at equilibrium cost of funds $R_{G}+\rho_{H}$ is given by ${ }^{13}$ :

$$
p_{1}^{B}\left(R_{G}+\rho_{H}\right)=\frac{R_{G}+\rho_{H}}{\pi_{H}}-1
$$

\footnotetext{
${ }^{13}$ Note that assumption A1 implies that $p_{1}^{B}>0$ for $\rho_{H}>0$.
} 
Firms with $p_{1} \in\left[p_{1}^{B}, p_{1}^{*}\right]$ compose the total demand for bank loans. The marginal firm risk-type $p_{1}^{*}$, which is indifferent between a bond issue or a bank loan is given by the solution to the equation:

$$
\widehat{R}_{2}\left(p_{1}\right)=R_{2}\left(p_{1}\right),
$$

since date $t=1$ financing terms are the same for bank loans or bonds $\left(\widehat{R}_{1}\left(p_{1}\right)=R_{1}\left(p_{1}\right)=\pi_{H}\right)$.

To see why all risk-types $p_{1} \in\left[p_{1}^{B}, p_{1}^{*}\right]$ prefer a bank loan to a bond issue, recall first that firms' financial choices are made by $H$-firms who know they are mimicked by $L$-firms of the same risk rating $p_{1}$. Second, in equilibrium the return on corporate bonds must be the same as on treasury bills:

$$
p_{1}\left(\nu R_{2}\left(p_{1}\right)+\pi_{H}\right)+\left(1-p_{1}\right) A=R_{G},
$$

and the return on all bank loans must be the same:

$$
p_{1}\left(\widehat{R}_{2}\left(p_{1}\right)+\pi_{H}\right)+\left(1-p_{1}\right) \pi_{H}=R_{G}+\rho_{H} .
$$

So that:

$$
R_{2}\left(p_{1}\right)=\frac{R_{G}-A-p_{1}\left(\pi_{H}-A\right)}{\nu}
$$

and

$$
\widehat{R}_{2}\left(p_{1}\right)=\frac{R_{G}+\rho_{H}-\pi_{H}}{p_{1}} .
$$

Condition (7) is thus equivalent to:

$$
R_{G}+\rho_{H}-\pi_{H}=\frac{R_{G}-A-p_{1}\left(\pi_{H}-A\right)}{\nu}
$$

implying that firm risk-types choosing bond financing are those with a higher rating $p_{1}$ :

$$
p_{1} \geq p_{1}^{*}\left(R_{G,} \rho_{H}\right) \text { where } p_{1}^{*}\left(R_{G}, \rho_{H}\right)=\frac{R_{G}-A-\nu\left(R_{G}+\rho_{H}-\pi_{H}\right)}{\pi_{H}-A} .
$$

For obvious reasons we shall restrict the analysis to the more plausible situation where $p_{1}^{*}\left(R_{G}, \rho_{H}\right)>p_{1}^{B 14}$.

\footnotetext{
${ }^{14}$ If intermediation costs were very large then $p_{1}^{*}\left(\rho_{H}\right) \leq p_{1}^{B}$ and there would be no banking sector in equilibrium. In this case the riskiest firms substitute bank lending for junk bond issues.
} 
Given that risk-types $p_{1}$ are uniformly distributed between 0 and 1 , the aggregate effective demand for bank loans is given by:

$$
p_{1}^{*}\left(R_{G,} \rho_{H}\right)-p_{1}^{B}\left(R_{G,} \rho_{H}\right)=\frac{R_{G}-A}{\pi_{H}-A}-\left(R_{G}+\rho_{H}-\pi_{H}\right)\left(\frac{(1+\nu) \pi_{H}-A}{\pi_{H}\left(\pi_{H}-A\right)}\right)
$$

Thus, equilibrium in the bank credit market requires that the aggregate supply of bank credit $L\left(R_{G}, \rho_{H}\right)$ equals aggregate demand, or:

$$
\begin{aligned}
L\left(R_{G}, \rho_{H}\right)= & \frac{1}{\pi_{H}-A}\left[\pi_{H}(1+\nu)-2 A-\right. \\
& \left.\frac{1}{\pi_{H}}\left(R_{G}\left(\nu \pi_{H}-A\right)+\rho_{H}\left((1+\nu) \pi_{H}-A\right)\right)\right] .
\end{aligned}
$$

Finally, when $\rho_{H}>0$ we have $L=\frac{w+E}{\kappa}$ and the bank credit equilibrium equation becomes ${ }^{15}$ :

$$
\begin{aligned}
\frac{w+E}{\kappa}= & \frac{1}{\pi_{H}-A}\left[\pi_{H}(1+\nu)-2 A-\right. \\
& \left.\frac{1}{\pi_{H}}\left(R_{G}\left(\nu \pi_{H}-A\right)+\rho_{H}\left((1+\nu) \pi_{H}-A\right)\right)\right] .
\end{aligned}
$$

Put more conveniently equation (9) defines a bank credit equilibrium schedule relating $\rho_{H}$ to $R_{G}$, which we denote by $\rho_{H}=C\left(R_{G}\right)$.

\subsection{Securities market equilibrium}

The demand for funds on this market is the sum of the demand by the highest rated risk-types $\left(1-p_{1}^{*}\left(R_{G}, \rho_{H}\right)\right)$ who issue corporate bonds, the demand by the Treasury $G$, and the demand by banks that issue bonds $B_{b}$ as well as equity $E$. The supply of funds is given by household savings $(1-d)$ on the one hand, and investments by the banking sector in Government bonds $G_{b}$ on the other.

The securities market equilibrium condition therefore is:

$$
1-d+G_{b}=1-p_{1}^{*}\left(R_{G}, \rho_{H}\right)+\left(B_{b}+E\right)+G
$$

\footnotetext{
${ }^{15}$ The characterization of equilibrium with $\rho_{H}=0$ is straightforward. To avoid discussing too many cases we do not report this case.
} 
Replacing $p_{1}^{*}\left(R_{G}, \rho_{H}\right)$ by its value and rearranging we obtain:

$$
(1-d)=1-\frac{R_{G}-A-\nu\left(R_{G}+\rho_{H}-\pi_{H}\right)}{\pi_{H}-A}+\left(B_{b}-G_{b}+E\right)+G
$$

To proceed further, we need to distinguish between the three cases where respectively $R_{G}>(1+c)+2 \frac{d}{b}, b(1+c) \leq R_{G} \leq b(1+c)+2 d$ and $R_{G}<1+c$, which correspond to different equilibrium levels of $R_{D}$.

- When $R_{G}>(1+c)+2 \frac{d}{b}$, all liquid household savings $d$ are deposited in the bank, so that $D\left(R_{D}\right)=d$ and the asset-liability constraint allow us to write (10) as follows:

$$
\frac{(1-\nu) R_{G}-A-\nu\left(\rho_{H}-\pi_{H}\right)}{\pi_{H}-A}=\left[\frac{w+E}{\kappa}-w\right]+G
$$

- When $R_{G}$ is in the intermediate range $(1+c) \leq R_{G} \leq(1+c)+2 \frac{d}{b}$, we obtain:

$$
\frac{(1-\nu) R_{G}-A-\nu\left(\rho_{H}-\pi_{H}\right)}{\pi_{H}-A}=\left[\frac{w+E}{\kappa}-w\right]+G+d-\frac{b}{2}\left(R_{G}-(1+c)\right)
$$

- Finally, when $R_{G}<1+c$ banks do not raise deposits and the securities market equilibrium equation (10) becomes:

$$
\frac{(1-\nu) R_{G}-A-\nu\left(\rho_{H}-\pi_{H}\right)}{\pi_{H}-A}=\left[\frac{w+E}{\kappa}-w\right]+G+d
$$

Equations $(12),(13)$ and (14) define a schedule relating $\rho_{H}$ to $R_{G}$, which we denote by $\rho_{H}=S\left(R_{G}\right)$. This function is increasing, continuous and piece-wise linear ${ }^{16}$.

\footnotetext{
${ }^{16}$ Again, to avoid discussing too many cases we shall only consider parameter values for which the equilibrium has $R_{D}>1$. For all these equilibria $R_{G} \geq 1+c$.
} 


\subsection{Existence and Uniqueness}

We can establish existence of a unique equilibrium in the capital market for any fixed level of bank equity issues $E$ that satisfies the following additional assumptions:

$$
\begin{array}{ll}
\mathrm{A} 2 & : \quad w+1-d \geq \frac{w+E}{\kappa}+G . \\
\mathrm{A} 3: & \quad G+d-w \geq 0
\end{array}
$$

These assumptions ensure inter alia that the amount of government borrowing $G$ is small enough that it does not crowd out the private sector issues of securities from banks and firms.

Proposition 1: A unique equilibrium exists for any given equity level $E$ whenever $w+1-d \geq \frac{w+E}{\kappa}+G$ and $G+d-w \geq 0$.

Proof. See the appendix.

One can immediately see why a unique equilibrium must exist when assumption A2 and A3 hold by looking at figure 1 below. This figure highlights that the credit market equilibrium schedule $\rho_{H}=C\left(R_{G}\right)$ is linearly downward sloping in $R_{G}$ and the securities market equilibrium schedule $\rho_{H}=S\left(R_{G}\right)$ is a piece-wise linear upward sloping function of $R_{G}$. Hence there must be a unique intersection point provided that $C^{-1}(0)>S^{-1}(0)+\delta(D)$. The proof in the Appendix establishes that this condition holds whenever assumptions A2 and A3 hold.

\section{Comparative Statics and the Effects of Monetary Policy}

Having characterized the general equilibrium given $E$ (the level of outside equity of banks) we are finally in a position to consider how monetary policy through open market operations may affect equilibrium investment. We can also analyze the comparative statics effects of changes in other parameters such as banks' stock of capital $(w+E)$, firms' collateral values $A$, or the extent of asymmetric information between firms and investors as measured by $\nu$. This analysis is again considerably simplified by referring to the above 


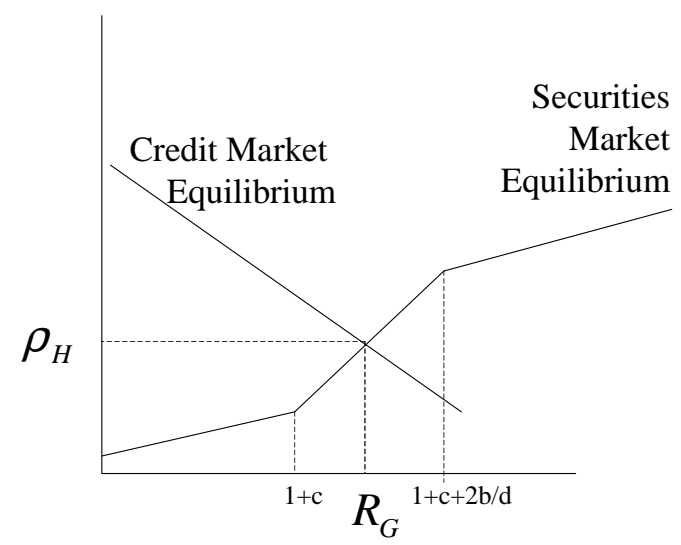

Figure 1:

diagram. Below we illustrate the comparative statics effects in diagrams. We confine the formal analysis to the appendix.

\section{- Open market operations}

We have in mind here a Central Bank holding a stock of T-bills and conducting monetary policy by buying and selling these bills against cash. An expansionary monetary policy is then implemented by buying T-bills (decreasing $G$ ) and a contractionary one by increasing $G$.

The effect of an increase in $G$ is displayed in figure 2 below.

The effect is to shift down the securities market equilibrium equation. The shift leads to a lower level of $\rho_{H}$ and an increase in $R_{G}$. These effects on $\rho_{H}$ and $R_{G}$ in turn affect the equilibrium segmentation of bank lending and bond issues by shifting overall financing to safer firms. That is, both $p_{1}^{B}\left(R_{G}+\rho_{H}\right)$ and $p_{1}^{*}\left(R_{G}+\rho_{H}\right)$ shift to the right by an amount proportional to the increase in $G$ (see the appendix), so that total bank lending remains unchanged, but the increased supply of T-bills crowds out corporate bond issues. Finally, the increase in $R_{G}$ induces banks to raise their remuneration on deposits and to rely more on deposits as a source of funds. 


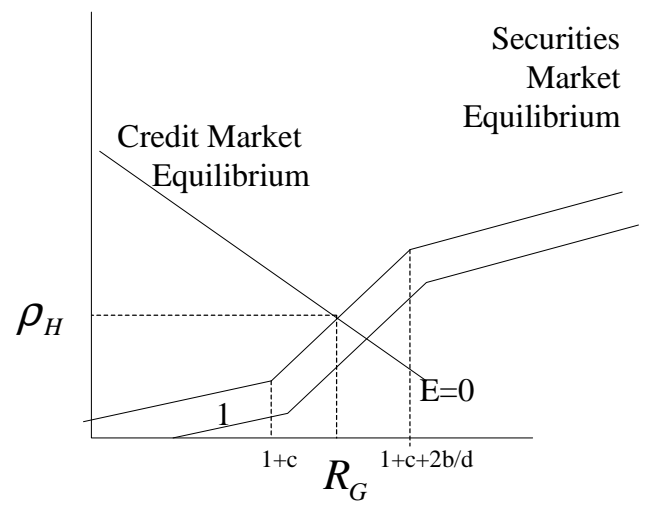

Figure 2:

Thus, the effect of a monetary tightening on individual firms is to cut off the riskiest firms from bank lending and to induce substitution of bond financing for relatively cheaper bank lending at the firms with the lowest bond ratings. Overall, the total share of bank lending to corporate bond issues increases in response to a monetary tightening.

The effect of the monetary tightening on banks is only to induce substitution of bank bond financing for greater deposit financing. Total lending to the corporate sector remains unchanged.

We summarize these finding in the following proposition.

Proposition 2: Effects of open market operations: A contractionary monetary policy (increase in $G$ ) has the effect of : i) increasing T-bill rates $R_{G}$, ii) decreasing bank spreads $\rho_{H}$, iii) increasing the overall cost of bank loans $R_{G}+\rho_{H}$, iv) decreasing corporate and bank bond issues by an amount superior to the additional amount of government borrowing, v) increasing bank deposits and, vi) leaving the aggregate amount of bank lending unchanged. However, bank lending is now directed to safer firms, so that on balance it is the marginal firms with the highest risks that are forced out of investment by the contractionary policy. 
Proof. See the appendix.

Perhaps the most interesting observation emerging from this analysis is that it is possible to observe a reduction in bank spreads at the same time as an increase in deposits and a reduction in total private investment. Here the only effect of the reduction in bank spreads is to change the composition of financing. There is a shift away from bond issues to borrowing through bank loans.

How do these results relate to empirical findings? The recent empirical literature on the monetary transmission mechanism has uncovered one broad finding on the composition effects of a contractionary policy. Kashyap, Stein and Wilkox (1993) have found that an important response to a monetary tightening is a surge in commercial paper issuance. They interpret this finding as a change in the composition of financing by firms in response to a monetary tightening: firms substituting bank debt for commercial paper. However, Gertler and Gilchrist (1994) and Oliner and Rudebusch (1995) find that the main factor behind this surge in commercial paper issuance is inventory build-up by large firms financed by commercial paper issuance. Small firms do not rely on commercial paper issues at all. Moreover, these firms bear the brunt of the monetary tightening. Thus, the story that seems to emerge from these studies is that:

"..the main effect of a monetary contraction is to shift financing of all types from small firms to large firms. This shift produces a decline in the aggregate bank-loan share because large firms rely less heavily on bank debt than do small firms." [Oliner and Rudebusch, pp 301]

Our results are consistent with these findings to the extent that they explain the shift in overall financing from small (or riskier) firms to large (or safer) firms that results from an increase in interest rates $R_{G}$. They seem, however, in contradiction with the empirical evidence to the extent that in our model the aggregate bank loan share increases as a result of the monetary tightening. But, note that our results concern the aggregate share of bank lending to long-term bond issues and not the share of bank lending to short term debt, which is the focus of the empirical literature. It is possible that the share of bank debt to long term bond issues rises with a lag following a monetary contraction even though the aggregate share to short term debt 
temporarily rises as a result of the temporary surge in inventory build-up by the larger firms. Unfortunately, we are not aware of any empirical study looking at the share of bank lending to long term corporate bonds, and how this share reacts to a monetary tightening. We plan to investigate this issue in future work.

Note also that our result that $\rho_{H}$ decreases in response to a monetary tightening is consistent with the stylized fact that the yield on bank loans is sticky relative to the Treasury rate. Our model thus provides an alternative explanation for the observed stickiness of bank loan rates.

\section{- Changes in capital requirements}

Monetary policy can also have an indirect effect on bank lending by changing banks' capital base. To the extent that monetary tightening increases the share of existing non-performing loans it may in turn reduce the equity capital of banks. Indeed, Bernanke and Lown (1991) among others have found evidence of reduced bank lending during the 1990 recession induced by such a contraction in bank capital.

As can be seen in figure 3 below, a decrease in banks' equity capital $(w+E)$ affects two different equations in the equilibrium: the credit market equilibrium equation, which shifts away from the origin and the securities market schedule, which also shifts away from the origin. The reason why the credit market equilibrium equation shifts away from the origin is that since the supply of credit decreases $\rho_{H}$ must increase for the credit market to clear. The second effect on the securities market can be explained by banks' decreased demand for funds when their capital constraint is tighter: this will lead to a decrease in $R_{G}$.

Vice versa, an increase in bank capital (or a decrease in capital requirements) leads to a reduction in bank spreads $\rho_{H}$, to an increase in $R_{G}$, and to an increase in bank lending as one might expect ${ }^{17}$. So the effect of a decrease in bank equity capital is the same as in Holmstrom and Tirole (1997).

\footnotetext{
${ }^{17}$ Note, however, that the effect on $R_{G}$ depends on the size of $\kappa$. As is shown in the appendix, we have

$$
\frac{d R_{G}}{d w}=\frac{1}{\kappa}\left[\left(\pi_{H}-A\right)-\kappa\left((1+\nu) \pi_{H}-A\right)\right]>0
$$

only for low values of $\kappa$.
} 


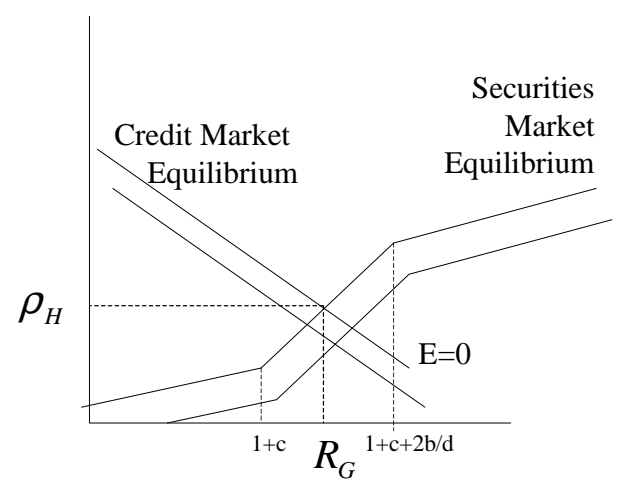

Figure 3:

\section{- Changes in collateral value}

As Gertler and Gilchrist (1993) and others have argued another indirect channel of monetary policy is the effect on firm collateral values and firms' borrowing capacity. One would expect that an increase in firms' collateral value $A$ would have the effect of raising the aggregate effective demand for investment funds by the corporate sector, since this tends to raise the expected value of corporate investments. This effect is indeed present for firms seeking bond financing, but note that it has no effect on bank lending in our model. The reason is that lending decisions are determined by $H$-type banks, who can perfectly screen $H$-type firms from $L$-type firms, and collateral value is irrelevant for $H$-type firms since they are never liquidated at date $t=1$.

As increases in collateral value increase the value of firms seeking bond financing one would expect that the share of bond financing relative to bank financing in the economy would increase as $A$ increases. This is indeed the case in our model:

$$
\operatorname{sign}\left[\frac{\partial p_{1}^{*}}{\partial A}\right]=\operatorname{sign}\left[-\left(\pi_{H}-R_{G}\right)+\nu\left(\pi_{H}-R_{G}-\rho_{H}\right)\right]<0
$$

since $\pi_{H}<R_{G}-\rho_{H}$. The net effect on $R_{G}$ and $\rho_{H}$ is harder to determine in general, as can be seen in the appendix. In an equilibrium with $R_{D}>1$ 
the likely effect, however, is that an increase in collateral values results in an increase in $R_{G}$ as a result of the increase in corporate bond issues and a reduction in $\rho_{H}$ because the bank lending segment gets pushed towards riskier firms. In the equilibrium with hoarding, $R_{G}$ remains unchanged but $\rho_{H}$ is likely to decrease for the same reason.

All in all, the indirect effects of monetary policy through changes in firm collateral values are likely to amplify the direct effects: a tightening of monetary policy is likely to reduce $A$ and thereby to reduce corporate bond issues and aggregate investment further.

\section{- Changes in informational dilution costs at the firm level}

To the extent that firm heterogeneity (and therefore asymmetric information) increases at the onset of a recession there may also be an indirect effect of monetary tightening through changes in $\nu$. The comparative statics with respect to $\nu$ are particularly simple in our model. Since bank rates are set by $H$-banks that have perfect monitoring ability, bank loan rates do not embody any dilution cost. In contrast, bond prices reflect the average probability of the second period cash flow, $\nu$. Therefore an increase in $\nu$, (that is, a decrease in dilution costs) would decrease the cost of bond financing leaving unchanged the cost of bank loans. This, in turn, makes bond financing relatively more attractive, so that $p_{1}^{*}$ decreases, the demand for credit decreases, and the demand for corporate bonds increases. Overall, when $\nu$ increases spreads on bank loans adjust downwards and the equilibrium rate on securities market $R_{G}$ adjusts upwards reacting to the increase in demand.

\section{- Changes in reserve requirements}

Changes in reserve requirements have two effects: they increase intermediation $\operatorname{costs} c$ and they change banks available deposits $d$. Therefore, the effect of changes in reserve requirements is identical to a combined change in $d$ and $c$. The resulting increase in the cost of deposits tends to induce banks to shift towards bond financing. This is the expected effect when bonds are perfect substitutes for deposits ( see Romer and Romer (1990). A change in reserve requirements would have no effect on aggregate investment if reserves are in turn invested in T-bills. If, however, they are held in cash then changes in reserve requirements are analogous to changes in $G$. In sum, changes in reserve 
requirements are either ineffective or equivalent to an open market operation. In other words, reserve requirements are a redundant policy instrument in our model.

\section{Endogenous bank equity}

Given that bank equity capital is such an important determinant of bank lending it is important to understand banks' equity issue decisions. We turn to this question in this section. We begin by considering banks' incentives to issue new equity. We then derive the aggregate supply of bank credit with endogenous bank equity capital. We show that there is a critical cut-off point $\rho_{H}^{1}$ at which a representative bank decides to switch from an equity base $w$ with no outside equity to one with outside equity $\bar{E}$. In other words, if the bank spread is high enough and bank loans are sufficiently lucrative then $H$-banks are prepared to pay a dilution cost in issuing equity in order to expand a profitable bank lending business. Similarly, we show that there is a critical cut-off point $\rho_{H}^{2}<\rho_{H}^{1}$ at which a representative bank with equity base $w+\bar{E}$ decides to repurchase its outside equity $\bar{E}$ in order to reduce dilution.

Because of the difference in the two cut-offs it is possible to obtain multiple pooling equilibria. One with a high spread, low bank equity capital and low aggregate bank lending and the other with a low spread, high bank equity capital and high aggregate bank lending. We refer to the former equilibrium as a "bank capital crunch" equilibrium.

\subsection{Optimal equity issues}

Recall that equity issues are determined by $H$-banks, who know they are being mimicked by $L$-banks. To use simpler notation, we shall denote by $\Gamma_{J}$ the return on capital of a type $J$ bank (where $J=H, L$ ). Thus,

$$
\Gamma_{J}=\frac{R_{G}+\rho_{J}}{\kappa}-\left(\frac{1}{\kappa}-1\right) R_{G}+\left(R_{G}-\left(R_{D}+c\right)\right) b\left(R_{D}-1\right)
$$

when $\rho_{H}>0$ and $1+c \leq R_{G} \leq 1+c+2 \frac{b}{d}$. The first two terms represents the unit return from lending given that the bank is borrowing in the bond market. The last term is the profit on deposits. 
The market value of bank equity is then simply equal to the expected discounted return on capital. If a bank raises funds $E$ by issuing equity, then in a perfect capital market new shareholders own a fraction of the bank's capital $\alpha$, equal to:

$$
\alpha \Gamma_{E}(w+E)=E R_{G}
$$

where $\Gamma_{E}$ denotes the market's expected return on capital for a bank raising new equity $E$. If we denote by $\delta_{H}(\widehat{R}, E)$ and $\delta_{L}(\widehat{R}, E)$ the conditional beliefs of new shareholders about the bank's type then $\Gamma_{E}=\delta_{H}(\widehat{R}, E) \Gamma_{H}+$ $\delta_{L}(\widehat{R}, E) \Gamma_{L}$.

An $H$-bank manager's expected payoff from issuing $E$ is therefore:

$$
(1-\alpha)\left[\lambda \Gamma_{E}+(1-\lambda) \Gamma_{H}\right](w+E)
$$

or, substituting for the value of $\alpha$ in (15) and rearranging, the manager's payoff is:

$$
V_{H}(E)=\frac{\Gamma_{E}(w+E)-E R_{G}}{\Gamma_{E}}\left[\lambda \Gamma_{E}+(1-\lambda) \Gamma_{H}\right]
$$

Thus, given market expectations $\Gamma_{E}$, an $H$-bank manager is better off issuing equity $E>0$ than issuing no additional equity if and only if,

$$
\frac{\Gamma_{E}(w+E)-E R_{G}}{\Gamma_{E}}\left[\lambda \Gamma_{E}+(1-\lambda) \Gamma_{H}\right] \geq\left[\lambda \Gamma_{0}+(1-\lambda) \Gamma_{H}\right] w
$$

Under the same market expectations, an $L$-bank manager decides to issue equity $E>0$ if and only if,

$$
\Gamma_{E}(w+E)-E R_{G} \geq \Gamma_{0} w
$$

Conditions (17) and (18) differ because a manager of an $L$-bank is better off selling his equity stake at date $t=1$ than holding on to it until date $t=2$, irrespectively of whether he has a liquidity need at date $t=1$, since the market always (weakly) overvalues the shares of an $L$-bank.

We can simplify condition (18) and obtain:

$$
\left(\Gamma_{E}-R_{G}\right) E \geq\left(\Gamma_{0}-\Gamma_{E}\right) w .
$$




\subsection{Aggregate credit supply}

We are now in a position to derive the equilibrium supply of bank loans, by characterizing the Bayesian-Nash equilibrium of the sequential game banks play by setting lending terms $\widehat{\mathbf{R}}^{H}=\left\{R_{2}(H)\right\}, \widehat{\mathbf{R}}^{L}=\left\{R_{2}(L)\right\}$ in a first stage, determining their choice of investments in a second, and finally by choosing the amount of new equity they want to issue, given $\widehat{\mathbf{R}}, R_{G}$, and $R_{D}$.

Several remarks are in order about this game.

First, this is a price setting game among (potentially) capacity constrained financial intermediaries. There are unfortunately a number of potential difficulties with analyzing such games. For example, firms applying for a loan at a bank offering better terms than others are not sure to get a loan since the bank may have a limited lending capacity and there are too many applicants. So, one question in this set-up is to determine how firms should respond to more attractive offers. Another problem is the characterization of a bank's best response function in the price setting stage stage.

Second, the game banks play here also has elements of a multidimensional signalling game, since banks may signal their type either through their lending terms $\widehat{\mathbf{R}}$ in the price setting stage or through the amount of equity they issue $E$ in the final stage. Again, there are potential difficulties associated with the analysis of such multidimensional signalling games.

To characterize this somewhat complex equilibrium it is therefore helpful to proceed in two steps. First, we begin by setting lending terms $\widehat{\mathbf{R}}^{H}=$ $\widehat{\mathbf{R}}^{L}=\widehat{\mathbf{R}}$ exogenously and characterize banks' optimal choice of investments and new equity issues given $\widehat{\mathbf{R}}$. Second, we determine the lending terms $\widehat{\mathbf{R}}$ that clear the market for bank loans and that can be supported as a pooling equilibrium $^{18}$.

Before describing this equilibrium in greater detail we need to give a more precise definition of equilibrium.

Definition: A Bayesian-Nash Equilibrium in the banking sector is characterized by:

- banks' best pricing strategies at stage $1, \widehat{\mathbf{R}}^{H}, \widehat{\mathbf{R}}^{L}$.

- banks' best investment strategies at stage 2

\footnotetext{
${ }^{18}$ In other words, the terms $\widehat{\mathbf{R}}$ must be such that neither bank type wants to deviate by offering other lending terms.
} 
- banks' best equity issue strategies at stage $3, E^{i} \in[0, \bar{E}], i=H, L$.

- The conditional beliefs of the capital market about the bank's type, $\left(\delta_{H}(\mathbf{R}, E)\right.$ and $\left.\delta_{L}(\mathbf{R}, E)\right)$.

Each bank type's equilibrium strategy must be a best response to the other banks' equilibrium strategies, given the market's conditional beliefs. Moreover, the market's conditional beliefs must be consistent with Bayesian updating.

The only equilibria we obtain are such that both types of banks offer the same lending terms $\mathbf{R}^{H}=\mathbf{R}^{L}=\mathbf{R}$ in the price setting stage. In any of these equilibria, neither firms nor equity investors are able to identify a bank's type from it's lending policy. These equilibria are either pooling equilibria, where both types of banks make the same equity issue decisions, $E^{H}=E^{L}=$ $E$ or semi-separating equilibria, where $H$-type banks partially separate by randomizing between two levels of equity issues. As usual, pooling equilibria can be supported by out-of-equilibrium beliefs such that $\delta_{H}(\widehat{\mathbf{R}}, \widehat{E})=0$ and $\delta_{L}(\widehat{\mathbf{R}}, \widehat{E})=1$ for all $\widehat{\mathbf{R}} \neq \mathbf{R}$ and $\widehat{E} \neq E$. Mixed strategy semi-separating equilibria also exists if the return of $L$-banks is allowed to be negative, which is the case under our assumptions ${ }^{19}$.

In deriving a bank type's equilibrium equity issue we assume, as is standard, that the bank is able to lend all its available funds at an expected equilibrium return per loan of $\rho_{H}$ for an $H$-bank and $\rho_{L}$ for an $L$-bank. In equilibrium lending terms $\rho_{H}^{*}$ and $\rho_{L}^{*}$ are such that the aggregate supply of bank credit is equal to aggregate demand for bank loans. At these terms each bank is then justified in assuming that it is able to lend all its' available funds. These terms $\mathbf{R}^{*}$ (or $\rho_{H}^{*}$ and $\rho_{L}^{*}$ ) are then fully general equilibrium terms if neither bank type has an incentive to deviate by offering different terms ${ }^{20}$.

\footnotetext{
${ }^{19}$ Note that the timing of moves specified here is crucial to obtain semi-separating equilibria. If the bank's investment choice was made at a later stage or was not observable, $L$-banks would invest in bonds and obtain at least a zero return. This would then upset the semi-separating equilibrium.

${ }^{20}$ Note that a necessary condition to obtain our equilibria is that the demand for bank loans by $H$-firms is greater than or equal to the total supply of bank credit by $H$-banks. Otherwise, our presumption that $H$-banks get a return on their loans of $\rho_{H}^{*}$ is false. As long as the proportion of $H$-banks is small enough and the proportion of $H$-firms high enough this condition will always be satisfied.
} 
We now turn to the characterization of equilibrium equity issues for a fixed $\mathbf{R}$ in a pooling equilibrium. We derive this best response $E(\mathbf{R})$ by fixing out-of equilibrium beliefs such that $\delta_{H}(\mathbf{R}, \widehat{E})=0$ and $\delta_{L}(\mathbf{R}, \widehat{E})=1$ for all $\widehat{E} \neq E(\mathbf{R})$. As one might expect, because out-of-equilibrium beliefs can be chosen arbitrarily, we may obtain infinitely many pooling equilibria. However, we single out the best pooling equilibrium from the point of view of an $H$-Bank (given that $L$-banks mimic this choice and, thus, dilute the value of $H$-banks' equity $)^{21}$. It turns out that the optimal equity issue for a type $H$ bank in a pooling equilibrium is either 0 or $\bar{E}$. This is established in the following lemma.

Lemma 2: For a given perceived return $\rho_{E}$, the optimal equity issue for an $H$-bank given lending terms $\mathbf{R}$ is either $\bar{E}$ if $\Gamma_{E}$ is larger than $R_{G} ; 0$ if $\Gamma_{E}$ is lower than $R_{G}$, or undetermined if $\Gamma_{E}=R_{G}$.

Proof. The sign of the derivative with respect to $E$ of (16) is equal to the sign of $\Gamma_{E}-R_{G}$.

In light of lemma 2 , we are able to derive a particularly simple aggregate bank credit supply schedule. We denote by $\rho_{H}^{1}$ the cut-off at which an $H$-bank prefers choosing $E=\bar{E}$ to $E=0$, even if by deviating it is perceived as an $L$-bank. Thus $\rho_{H}^{1}$ solves the following equation

$$
\frac{\Gamma_{L}(w+E)-E R_{G}}{\Gamma_{L}}\left[\lambda \Gamma_{L}+(1-\lambda) \Gamma_{H}\right]=\left[\lambda \Gamma_{0}+(1-\lambda) \Gamma_{H}\right] w
$$

where,

$$
\begin{gathered}
\Gamma_{H}=\frac{R_{G}+\rho_{H}^{1}}{\kappa}-\left(\frac{1}{\kappa}-1\right)\left(R_{D}+c\right), \\
\Gamma_{L}=\frac{1}{\kappa}\left[R_{G}+\widehat{\nu} \rho_{H}^{1}+(1-\widehat{\nu})\left(\bar{\pi}\left(p_{1}\right)+A-R_{G}\right)\right]-\left(\frac{1}{\kappa}-1\right)\left(R_{D}+c\right),
\end{gathered}
$$

and

$$
\begin{aligned}
\Gamma_{0}= & \frac{1}{\kappa}\left[R_{G}+\left(\frac{m}{m+M}\right)\left(\widehat{\nu} \rho_{H}^{1}+(1-\widehat{\nu})\left(\bar{\pi}\left(p_{1}\right)+A-R_{G}\right)\right)\right. \\
& \left.+\left(\frac{M}{m+M}\right) \rho_{H}^{1}\right]-\left(\frac{1}{\kappa}-1\right)\left(R_{D}+c\right) .
\end{aligned}
$$

\footnotetext{
${ }^{21}$ Note that a common refinement criterion, such as Cho and Kreps' intuitive criterion would select this equilibrium over all other pooling equilibria in our game (see Cho and Kreps (1987)).
} 
Below the cut-off $\rho_{H}^{1}$ choosing $E=0$ is the best response for an $H$-bank. Conversely, $\rho_{H}^{2}$ is the cut-off at which an $H$-bank prefers $E=0$ to $E=\bar{E}$, even if by deviating it is perceived as an $L$-bank. That is, $\rho_{H}^{2}$ solves the equation

$$
\frac{\Gamma_{\bar{E}}(w+E)-E R_{G}}{\Gamma_{\bar{E}}}\left[\lambda \Gamma_{\bar{E}}+(1-\lambda) \Gamma_{H}\right]=\left[\lambda \Gamma_{L}+(1-\lambda) \Gamma_{H}\right] w
$$

where,

$$
\begin{aligned}
\Gamma_{\bar{E}}= & \frac{1}{\kappa}\left[R_{G}+\left(\frac{m}{m+M}\right)\left(\widehat{\nu} \rho_{H}^{2}+(1-\widehat{\nu})\left(\bar{\pi}\left(p_{1}\right)+A-R_{G}\right)\right)\right. \\
& \left.+\left(\frac{M}{m+M}\right) \rho_{H}^{2}\right]-\left(\frac{1}{\kappa}-1\right)\left(R_{D}+c\right) .
\end{aligned}
$$

The total supply of funds from the banking sector for $\rho_{H} \geq \rho_{H}^{1}$ is then $\frac{w+\bar{E}}{\kappa}$. Similarly, below the cut-off $\rho_{H}^{2}$ an equity issue $E=0$ is the best response for $H$-banks. Then the total supply of bank credit is $\frac{w}{\kappa}$.

Now, to determine whether a general (pooling) equilibrium exists for $\rho_{H}^{*} \geq$ $\rho_{H}^{1}$ or $\rho_{H}^{*} \leq \rho_{H}^{2}$ we need to check that:

1) aggregate demand for bank loans equals aggregate supply at terms $\mathbf{R}^{*}$,

2) neither type of bank has an incentive to deviate by offering different lending terms in stage 1 , and

3) neither type of bank has an incentive to deviate by choosing a different portfolio of investments in stage 2 .

When out-of-equilibrium beliefs are such that $\delta_{H}\left(\mathbf{R}, E\left(\mathbf{R}^{*}\right)\right)=0$ and $\delta_{L}\left(\mathbf{R}, E\left(\mathbf{R}^{*}\right)\right)=1$ for all $\mathbf{R} \neq \mathbf{R}^{*}$, then deviation in stage 1 to new lending terms does not pay for either type of bank if the following condition holds:

$$
(\nu-\widehat{\nu})\left[R_{2}^{H}\left(p_{1}\right)-A\right] \frac{w}{\kappa}<\frac{M}{M+m}(1-\widehat{\nu})\left[\rho_{H}-\bar{\pi}\left(p_{1}\right)+1-A\right] \frac{w}{\kappa}
$$

The LHS of this inequality is the maximum gain for an $L$-bank of a deviation: by slightly undercutting $\mathbf{R}^{*}$ the $L$-bank is able to improve the average quality of its loan applicants from a proportion $\widehat{\nu}$ of $H$-firms to a proportion $\nu$ and, thus, to raise its payoff. The RHS is the minimum cost to an $L$-bank from such a deviation: it represents the capital loss on its equity from being identified as an $L$-bank. 
Similarly, deviation in stage 2 to a different portfolio of investments is unattractive if

$$
-\rho_{L} \frac{w}{\kappa}<\frac{M}{M+m}(1-\widehat{\nu})\left[\rho_{H}-\bar{\pi}\left(p_{1}\right)+1-A\right] \frac{w}{\kappa} .
$$

The LHS of this inequality represents the maximum gain for an $L$-type banker from investing all available funds in bonds rather than bank loans. The RHS as before represents the minimum capital loss on equity from being identified as an $L$-bank. Conditions (19) and (20) are sufficient to guarantee existence and are henceforth assumed to hold.

The next proposition establishes that the cut-offs are such that $\rho_{H}^{2}<\rho_{H}^{1}$, so that multiple equilibria may exist on the interval $\left[\rho_{H}^{2}, \rho_{H}^{1}\right]$. There may then be two pooling equilibria, one with $E^{*}=0$ and the other with $E^{*}=\bar{E}$. A semi-separating equilibrium may also exist in which $H$-banks are indifferent between setting $E=\bar{E}$ or $E=0$ and only a fraction chooses $E=\bar{E}$, while all $L$-banks choose $E=\bar{E}$. In this semi-separating equilibrium total bank credit supply lies between $\frac{w}{\kappa}$ and $\frac{w+\bar{E}}{\kappa}$, with the fraction of $H$-banks choosing $E=\bar{E}$ being such that aggregate bank credit supply equals aggregate demand.

Proposition 3: Let $\rho_{\bar{E}}=\delta_{H}(\mathbf{R}, \bar{E}) \rho_{H}+\delta_{L}(\mathbf{R}, \bar{E}) \rho_{L}$ denote the equilibrium expected return per loan of a bank issuing new equity worth $\bar{E}$. And let out-of-equilibrium beliefs be such that $\delta_{H}(\mathbf{R}, \widehat{E})=0$ and $\delta_{L}(\mathbf{R}, \widehat{E})=1$ for all $\widehat{E} \neq \bar{E}$. Then the aggregate bank-credit supply function $L()$ in a pooling equilibrium is: $\left\{\begin{array}{ll}L\left(\rho_{H}\right)=\frac{w}{\kappa} & \text { for } \rho_{H} \leq \rho_{H}^{2} \\ L\left(\rho_{H}\right)=\frac{w+\bar{E}}{\kappa} & \text { for } \rho_{H} \geq \rho_{H}^{1}\end{array}\right\}$

with $\rho_{H}^{2}<\rho_{H}^{1}$, and aggregate supply in a semi-separating equilibrium is given by:

$$
L\left(\rho_{H}\right) \in\left[\frac{w}{\kappa}, \frac{w+\bar{E}}{\kappa}\right] \text { for }\left(\rho_{H}, \rho_{L}\right) \text { such that } \frac{M}{M+m} \rho_{H}+\frac{m}{M+m} \rho_{L}=0 .
$$

Proof. See the appendix.

The source of multiplicity of equilibria in the interval $\left[\rho_{H}^{1}, \rho_{H}^{2}\right]$ is, as in all signalling games, due to the degree of freedom in specifying out-ofequilibrium beliefs ${ }^{22}$. An equilibrium best-response of $\bar{E}$ is supported by

\footnotetext{
${ }^{22}$ If $\rho_{L} \geq 0$ then $\rho_{\bar{E}}>0$ so that the equilibrium set only contains the two pooling equilibria. The aggregate bank credit supply correspondence is then discontinuous, giving rise potentially to problems of existence of equilibrium.
} 
out-of-equilibrium beliefs $\delta_{H}(\mathbf{R}, \widehat{E})=0$ and $\delta_{L}(\mathbf{R}, \widehat{E})=1$ for all $\widehat{E} \neq \bar{E}$. On the other hand, an equilibrium best-response of 0 is supported by outof-equilibrium beliefs $\delta_{H}(\mathbf{R}, \widehat{E})=0$ and $\delta_{L}(\mathbf{R}, \widehat{E})=1$ for all $\widehat{E} \neq 0$. Given that we have different out-of-equilibrium beliefs supporting each equilibrium it is not entirely surprising that we should obtain two cut-offs $\rho_{H}^{1}>\rho_{H}^{2}$.

Since in our model the level of bank equity depends on the equilibrium level of $\rho_{H}^{*}$ a contractionary monetary policy leading to a reduction in $\rho_{H}$ may in turn trigger a decrease or prevent an increase in the level of bank equity, and thus lead to a magnified contractionary effect. In particular it can provoke the onset of a bank capital crunch.

As Figure 4 highlights, if the equilibrium level of equity issued by banks is $E^{*}=\bar{E}$ the security market and the credit market curves are shifted downwards.

Proposition 4: Within some range of parameter values, there are at least two equilibria. A switch from the equilibrium with no bank equity issues to the equilibrium with outside equity issues induces a decrease in banks' spreads.

Proof. Omitted. (The effect is the same as an exogenous increase in capital illustrated in figure 3).

We interpret the switch from the equilibrium with outside equity capital to the one without equity issues as a form of credit crunch induced by a bank equity crunch. The "bank equity crunch" equilibrium is characterized by a low level of lending, a low level of bank capital and high profitability on bank lending.

A contractionary monetary policy which leads to an increase in $R_{G}$ and a reduction in $\rho_{H}$ may trigger a decrease (or prevent an increase) in bank equity, and thus lead to a magnified contractionary effect, whenever $\rho_{H}$ falls below $\rho_{H}^{2}$ or $\rho_{H}^{1}$. In particular it can provoke the onset of a credit crunch. Note that this in contrast to the effects expected in a standard bank lending channel model based on changes in bank liquidity. In such a model monetary tightening is equivalent to a reduction in bank liquidity, which would result in an increase in $\rho_{H}$, and therefore might be partially offset by an increase in bank capital. 


\section{Conclusion}

This paper proposes a model of the interface between corporate financing decisions and monetary policy in a general equilibrium model (of the capital market), which traces the effects of monetary policy on firms' investment decisions.

The model developed here, which abstracts from many other relevant considerations generates several qualitative predictions about the joint equilibrium in the credit and securities markets and the effects of open market operations on the real sector, which are broadly consistent with stylized facts on the effects of monetary policy on investment and firm financing uncovered by recent empirical studies.

The model considered in this paper is already somewhat complex and we have chosen to leave some interesting extensions for future research. An obvious immediate extension is to differentiate firms according to both the underlying risk of their cash flows and their size. If, in addition, one then introduces a fixed issuing cost for bonds (representing legal and administrative costs) we would expect to obtain an equilibrium segmentation where only the largest and safest firms issue bonds. Such a model could also be used to investigate how the size distribution of firms as well as the relative costs of securitization affect the aggregate composition of financing in the economy.

Another obvious but more ambitious extension is to introduce a final goods market and a household sector, which responds to changes in interest rates by altering its consumption/savings decisions. Extending the model to a multiperiod setting in order to explore the dynamics of the monetary transmission mechanism is perhaps the most interesting and difficult challenge.

\section{Mathematical Appendix}

Proof of Proposition 1: Using again $\rho_{H}=C\left(R_{G}\right)$ and $\rho_{H}=$ $S\left(R_{G}\right)$ to represent equations (9) and (13) respectively, existence and uniqueness of a solution $\left(\rho_{H}, R_{G}\right)$ is straightforward, we have $C\left(R_{G}\right)-S\left(R_{G}\right)$ is a continuous decreasing function satisfying $C(M)-S(M)<0$ for a value of $M$ large enough. Under Assumption 2 it is easy to prove, as we will establish below that $C(0)-S(0)>0$ and thus there exists $R_{G}$ such that $C\left(R_{G}\right)-$ $S\left(R_{G}\right)=0$. This solution in turn determines $R_{D}$ and $B_{b}-G_{b}$. 
Therefore, we only need to establish that $\rho_{H}>0, R_{G}>0$. Since $C()$ is decreasing and $S()$ is increasing, a sufficient condition for $\rho_{H}>0$ is that $C^{-1}(0)>S^{-1}(0)$, and symmetrically, a condition for $R_{G}>0$ is $C(0)>S(0)$.

- We will first proceed to show that condition $C^{-1}(0)>S^{-1}(0)$ is satisfied under Assumption 2. Indeed, from equations (14) and (9) we have:

$\left.S^{-1}(0) \leq \frac{1}{(1-\nu)+\gamma\left(\pi_{H}-A\right)}\left[\left(\pi_{H}-A\right)\left(\left[\frac{w+E}{\kappa}-w\right]+G+d\right)\right)+A-\nu \pi_{H}\right]$

where $\gamma=\frac{b}{2}$ or 0 depending on the values of $R_{G}$,

$$
C^{-1}(0)=\frac{\pi_{H}}{\nu \pi_{H}-A}\left[\pi_{H}(1+\nu)-2 A-\left(\pi_{H}-A\right) \frac{w+E}{\kappa}\right]
$$

so that $C^{-1}(0)>S^{-1}(0)$ if

$$
\begin{gathered}
{\left[(1-\nu)+\gamma\left(\pi_{H}-A\right)\right] \pi_{H}\left[\pi_{H}(1+\nu)-2 A-\left(\pi_{H}-A\right) \frac{w+E}{\kappa}\right]>} \\
\left.\left(\nu \pi_{H}-A\right)\left[\left(\pi_{H}-A\right)\left(\left[\frac{w+E}{\kappa}-w\right]+G+d\right)\right)+A-\nu \pi_{H}\right] .
\end{gathered}
$$

The term

$$
\left.\pi_{H}^{2}(1+\nu)-2 \pi_{H} A-\nu \pi_{H}\left(\pi_{H}(1+\nu)-2 A\right)\right)+\left(\nu \pi_{H}-A\right)^{2}
$$

simplifies to $\left(\pi_{H}-A\right)^{2}$ so that, after dividing by $\left(\pi_{H}-A\right)$, we obtain the following condition

$\gamma \pi_{H}\left[\pi_{H}(1+\nu)-2 A\right]+\left(\pi_{H}-A\right)\left(1-(1+\gamma) \frac{w+E}{\kappa}\right)>\left(\nu \pi_{H}-A\right)(G+d-w)$.

Since

$$
\pi_{H}\left[\pi_{H}(1+\nu)-2 A\right]>\left(\pi_{H}-A\right) \frac{w+E}{\kappa}
$$

the left hand side of the above inequality is at a minimum for $\gamma=0$ and we obtain the following sufficient condition:

$$
\left(\pi_{H}-A\right)\left(1-\frac{w+E}{\kappa}\right)>\left(\nu \pi_{H}-A\right)(G+d-w) .
$$


Recalling that $\pi_{H}-A>\nu \pi_{H}-A$ and that $1 \geq \frac{w+E}{\kappa}$, it follows that assumption

$$
\mathrm{A} 2: 1-d+w \geq \frac{w+E}{\kappa}+G .
$$

implies that $C^{-1}(0)>S^{-1}(0)$ and $\rho_{H} \geq 0$.

- Next we proceed to show that $C(0)>S(0)$. We have

$$
C(0)=\frac{\pi_{H}}{(1+\nu) \pi_{H}-A}\left[\pi_{H}(1+\nu)-2 A-\left(\pi_{H}-A\right) \frac{w+E}{\kappa}\right]
$$

and

$$
\left.S(0)=\frac{1}{\nu}\left[\left(\nu \pi_{H}-A\right)-\left(\pi_{H}-A\right)\left(\frac{w+E}{\kappa}-w+G+d\right)\right)\right]
$$

Thus, we must show that

$$
\begin{gathered}
\nu \pi_{H}\left[\pi_{H}(1+\nu)-2 A-\left(\pi_{H}-A\right) \frac{w+E}{\kappa}\right]> \\
\left.\left((1+\nu) \pi_{H}-A\right)\left[\left(\nu \pi_{H}-A\right)-\left(\pi_{H}-A\right)\left(\frac{w+E}{\kappa}-w+G+d\right)\right)\right]
\end{gathered}
$$

In the above expression, the term

$$
\nu\left[\pi_{H}(1+\nu)-2 A\right]-\left((1+\nu) \pi_{H}-A\right)\left[\left(\nu \pi_{H}-A\right)\right.
$$

simplifies to

$$
A\left(\pi_{H}-A\right)>0 .
$$

The term

$$
\left(\pi_{H}-A\right) \frac{w+E}{\kappa}\left((1+\nu) \pi_{H}-A-\nu \pi_{H}\right)
$$

is also positive, so that a sufficient condition for $C(0)>S(0)$ is that the residual term is also non-negative:

$$
\left.\left((1+\nu) \pi_{H}-A\right)\left(\pi_{H}-A\right)(G+d-w)\right) \geq 0
$$

Under assumption A3 our condition holds and $R_{G}>0$.

Proof of the comparative statics propositions: We use Cramer's rule to prove the different comparative statics results in the equilibrium where $R_{D}>1$. 
Define first the functions $\Phi\left(R_{G}, \rho_{H}\right)$ and $\Omega\left(R_{G}, \rho_{H}\right)$ from equations (9) and (13) so that both have zero on the RHS:

$$
\begin{aligned}
& \Phi\left(R_{G}, \rho_{H}\right) \equiv R_{G}\left(\nu \pi_{H}-A\right)+\rho_{H}\left((1+\nu) \pi_{H}-A\right) \\
& +\pi_{H}\left[\left(\pi_{H}-A\right)\left(\frac{w+E}{\kappa}\right)-\left(\pi_{H}(1+\nu)-2 A\right)\right] \\
& =0 \\
& \Omega\left(R_{G}, \rho_{H}\right) \equiv \frac{R_{G}(1-\nu)-\nu\left(\rho_{H}-\pi_{H}\right)-A}{\pi_{H}-A}-\left[\frac{w+E}{\kappa}-w\right] \\
& -G-d+\frac{b}{2}\left(R_{G}-(1+c)\right) \\
& =0
\end{aligned}
$$

Then:

$$
\left[\begin{array}{cc}
\left(\nu \pi_{H}-A\right) & \left((1+\nu) \pi_{H}-A\right) \\
\frac{1-\nu}{\pi_{H}-A}+\frac{b}{2} & -\frac{\nu}{\pi_{H}-A}
\end{array}\right]\left[\begin{array}{l}
d R_{G} \\
d \rho_{H}
\end{array}\right]=\left[\begin{array}{c}
-\frac{\partial \Phi}{\partial x} \\
-\frac{\partial \Omega}{\partial x}
\end{array}\right] d x
$$

The solution for every exogenous variable is then easily found using Cramer's rule since the determinant of the principal matrix is equal to -1 .

- Case $x=G$.

We obtain: $\left[\begin{array}{c}-\frac{\partial \Phi}{\partial G} \\ -\frac{\partial \Omega}{\partial G}\end{array}\right]=\left[\begin{array}{l}0 \\ 1\end{array}\right]$ so that:

$$
\begin{gathered}
\frac{d R_{G}}{d G}=(1+\nu) \pi_{H}-A>0, \\
\frac{d \rho_{H}}{d G}=-\left(\nu \pi_{H}-A\right)<0
\end{gathered}
$$

and

$$
\frac{d\left(R_{G}+\rho_{H}\right)}{d G}=\pi_{H}>0 .
$$


The effect on $p_{1}^{*}$ and $p_{1}^{B}$ of a change in $G$ is thus:

$$
\begin{gathered}
\frac{d p_{1}^{*}}{d G}=\frac{1-\nu}{\pi_{H}-A} \frac{d R_{G}}{d G}-\frac{\nu}{\pi_{H}-A} \frac{d \rho_{H}}{d G} \\
\frac{d p_{1}^{*}}{d G}=\frac{1}{\pi_{H}-A}\left[(1-\nu)\left[(1+\nu) \pi_{H}-A\right]+\nu\left(\nu \pi_{H}-A\right)\right]=1
\end{gathered}
$$

and,

$$
\frac{d p_{1}^{B}}{d G}=\frac{1}{\pi_{H}}\left[\frac{d\left(R_{G}+\rho_{H}\right)}{d G}\right]=1 .
$$

In words, there is a shift of bank lending towards safer firms proportional to G.

- Case $x=w$.

We obtain: $\left[\begin{array}{c}-\frac{\partial \Phi}{\partial w} \\ -\frac{\partial \Omega}{\partial w}\end{array}\right]=\left[\begin{array}{c}-\frac{\pi_{H}\left(\pi_{H}-A\right)}{\kappa} \\ \frac{1-\kappa}{\kappa}\end{array}\right]$

so that

$$
\frac{d R_{G}}{d w}=-\left[\frac{\pi_{H}\left(\pi_{H}-A\right)}{\kappa} \frac{\nu}{\pi_{H}-A}-\frac{1-\kappa}{\kappa}\left((1+\nu) \pi_{H}-A\right)\right]
$$

or,

$$
\begin{gathered}
\frac{d R_{G}}{d w}=\frac{1}{\kappa}\left[\left(\pi_{H}-A\right)-\kappa\left((1+\nu) \pi_{H}-A\right)\right]>0 \\
\frac{d \rho_{H}}{d w}=-\left[\left(\nu \pi_{H}-A\right) \frac{1-\kappa}{\kappa}+\frac{\pi_{H}\left(\pi_{H}-A\right)}{\kappa}\left(\frac{1-\nu}{\pi_{H}-A}+\frac{b}{2}\right)\right]
\end{gathered}
$$

or,

$$
\frac{d \rho_{H}}{d w}=\frac{1}{\kappa}\left[\kappa\left(\nu \pi_{H}-A\right)-\left(\pi_{H}-A\right)\right]-\frac{\pi_{H}\left(\pi_{H}-A\right)}{\kappa} \frac{b}{2}
$$

which is negative for low values of $\kappa$

- Case $x=A$. 
We obtain: $\left[\begin{array}{c}-\frac{\partial \Phi}{\partial A} \\ -\frac{\partial \Omega}{\partial A}\end{array}\right]=\left[\begin{array}{c}R_{G}+\rho_{H}+\pi_{H}\left(\frac{w+E}{\kappa}-2\right) \\ -\frac{\left(R_{G}-\pi_{H}\right)(1-\nu)-\nu \rho_{H}}{\left(\pi_{H}-A\right)^{2}}\end{array}\right]$

and

$$
\begin{aligned}
\frac{d R_{G}}{d A}= & \frac{1}{\left(\pi_{H}-A\right)^{2}}\left\{\nu\left(R_{G}+\rho_{H}+\pi_{H}\left(\frac{w+E}{\kappa}-2\right)\right)\left(\pi_{H}-A\right)\right. \\
& \left.-\left[(1-\nu)\left(R_{G}-\pi_{H}\right)-v \rho_{H}\right]\left(\pi_{H}(1+\nu)-A\right)\right\}
\end{aligned}
$$

or

$$
\begin{aligned}
\frac{d R_{G}}{d A}= & \frac{1}{\left(\pi_{H}-A\right)^{2}}\left\{\nu R_{G}\left(\pi_{H}-A\right)+\nu \rho_{H}\left(\pi_{H}-A\right)\right. \\
& +\nu \pi_{H}\left(\frac{w+E}{\kappa}-2\right)\left(\pi_{H}-A\right) \\
& \left.-(1-\nu)\left(R_{G}-\pi_{H}\right)\left(\pi_{H}(1+\nu)-A\right)+v \rho_{H}\left(\pi_{H}(1+\nu)-A\right)\right\}
\end{aligned}
$$

rearranging,

$$
\begin{aligned}
\frac{d R_{G}}{d A}= & \frac{1}{\left(\pi_{H}-A\right)^{2}}\left\{R_{G}\left(\pi_{H}(2 \nu-1+\nu(1-\nu))-A(2 \nu-1)\right)\right. \\
& +\rho_{H} \nu\left(\pi_{H}(2+\nu)-2 A\right) \\
& \left.+\left(\pi_{H}-A\right)\left[\pi_{H} \nu\left(\frac{w+E}{\kappa}-2\right)+\pi_{H}(1-\nu)\right]+(1-\nu) \nu \pi_{H}^{2}\right\}
\end{aligned}
$$

For high values of $\nu$ (higher than $\frac{1}{2}$ ) the first two terms in this expression are positive and may outweigh the third term, in which case $\frac{d R_{G}}{d A}>0$. Now, turning to the derivative of $\rho_{H}$ with respect to $A$, we have

$$
\begin{aligned}
\frac{d \rho_{H}}{d A}= & \frac{1}{\left(\pi_{H}-A\right)^{2}}\left\{\left[(1-\nu)\left(R_{G}-\pi_{H}\right)-\nu \rho_{H}\right]\left(\nu \pi_{H}-A\right)\right. \\
& \left.+\left((1-\nu)+\frac{b}{2}\left(\pi_{H}-A\right)\right)\left[\left(R_{G}+\rho_{H}\right)+\pi_{H}\left(\frac{w+E}{\kappa}-2\right)\right]\left(\pi_{H}-A\right)\right\}
\end{aligned}
$$

or, 


$$
\begin{aligned}
\frac{d \rho_{H}}{d A}= & \frac{1}{\left(\pi_{H}-A\right)^{2}}\left\{R_{G}(1-\nu)\left[\pi_{H}(1+\nu)-2 A\right]\right. \\
& +\rho_{H}\left[\pi_{H}-A-\nu\left((1+\nu) \pi_{H}-2 A\right)\right] \\
& \left.+(1-\nu) \pi_{H}\left[\left(\frac{w+E}{\kappa}-2\right)\right)\left(\pi_{H}-A\right)-\left(\nu \pi_{H}-A\right)\right] \\
& \left.+\frac{b}{2}\left[\left(R_{G}+\rho_{H}\right)+\pi_{H}\left(\frac{w+E}{\kappa}-2\right)\right]\right\}
\end{aligned}
$$

The first term is always positive. The second term is negative for high values of $\nu$. As for the third term, it is clearly negative since $1>\frac{w+E}{\kappa}$. The sign of the last term depends upon the precise value of $\pi_{H}$.

- Case $x=\nu$.

$$
\begin{gathered}
\text { We obtain: }\left[\begin{array}{c}
-\frac{\partial \Phi}{\partial \nu} \\
-\frac{\partial \Omega}{\partial \nu}
\end{array}\right]=\left(R_{G}+\rho_{H}-\pi_{H}\right)\left[\begin{array}{c}
-\pi_{H} \\
\frac{1}{\pi_{H}-A}
\end{array}\right] \\
\frac{d R_{G}}{d \nu}=-\left(R_{G}+\rho_{H}-\pi_{H}\right)\left[\frac{\nu \pi_{H}}{\pi_{H}-A}-\frac{1}{\pi_{H}-A}\left((1+\nu) \pi_{H}-A\right)\right] \\
\frac{d R_{G}}{d \nu}=\left(R_{G}+\rho_{H}-\pi_{H}\right)
\end{gathered}
$$

and $p_{1}^{B}>0$ implies $\frac{d R_{G}}{d \nu}>0$

and

$$
\begin{gathered}
\frac{d \rho_{H}}{d \nu}=-\left(R_{G}+\rho_{H}-\pi_{H}\right)\left[\left(\nu \pi_{H}-A\right) \frac{1}{\pi_{H}-A}+\pi_{H}\left(\frac{1-\nu}{\pi_{H}-A}+\frac{b}{2}\right)\right] \\
\frac{d \rho_{H}}{d \nu}=-\left(R_{G}+\rho_{H}-\pi_{H}\right)\left(1+\pi_{H} \frac{b}{2}\right)<0
\end{gathered}
$$

Notice that 


$$
\frac{d\left(R_{G}+\rho_{H}\right)}{d \nu}=\pi_{H} \frac{b}{2}<0 .
$$

Proof of Proposition 3: We begin by establishing existence of two pooling and a semi-separating equilibrium. We then proceed to show that the two pooling equilibria satisfy the inequality $\rho_{H}^{2}<\rho_{H}^{1}$. Let $\rho_{E}$ and $\rho_{0}$ be equity holders' equilibrium beliefs for a bank that issues an amount of equity respectively equal to $E$ and 0 . We define two functions $\psi_{H}$ and $\psi_{L}$ as follows:

$$
\begin{aligned}
\psi_{H}\left(\Gamma_{E}, \Gamma_{0}\right)= & \frac{\Gamma_{E}(w+E)-E}{\Gamma_{E}}\left[\lambda \Gamma_{E}+(1-\lambda) \Gamma_{H}\right] \\
& -\left[\lambda \Gamma_{0}+(1-\lambda) \Gamma_{H}\right] w
\end{aligned}
$$

or, equivalently,

$$
\begin{aligned}
\psi_{H}\left(\Gamma_{E}, \Gamma_{0}\right)= & \left(\Gamma_{E}-1\right) E\left[\lambda+(1-\lambda) \frac{\Gamma_{H}}{\Gamma_{E}}\right] \\
& -\lambda\left(\Gamma_{0}-\Gamma_{E}\right) w
\end{aligned}
$$

and

$$
\psi_{L}\left(\Gamma_{E}, \Gamma_{0}\right)=\left(\Gamma_{E}-1\right) E-\left(\Gamma_{0}-\Gamma_{E}\right) w
$$

which represent the net payoff of issuing equity worth $E=\bar{E}$ instead of $E=0$, for respectively an $H$ and an $L$-bank.

Our different types of equilibria are then characterized by the values of the functions $\psi_{H}$ and $\psi_{L}$, as follows:

1. The pooling equilibrium with $E=0$ is characterized by $\psi_{H}\left(\Gamma_{E}, \Gamma_{0}\right) \leq 0$ and $\psi_{L}\left(\Gamma_{E}, \Gamma_{0}\right) \leq 0$.

2. The pooling equilibrium with $E=\bar{E}$ by,

$$
\psi_{H}\left(\Gamma_{E}, \Gamma_{0}\right) \geq 0 \text { and } \psi_{L}\left(\Gamma_{E}, \Gamma_{0}\right) \geq 0
$$

3. Separating equilibria by different signs for the functions $\psi_{H}$ and $\psi_{L}$.

4. Semi-separating equilibria by a mixed strategy of one type of bank, which implies that either $\psi_{H}\left(\Gamma_{E}, \Gamma_{0}\right)=0$ or $\psi_{L}\left(\Gamma_{E}, \Gamma_{0}\right)=0$. 
To prove Proposition 3, we first establish a preliminary lemma:

Lemma 3: $i$ ) If $\Gamma_{E}>1$, then $\psi_{L}\left(\Gamma_{E}, \Gamma_{0}\right) \geq 0$ implies $\psi_{H}\left(\Gamma_{E}, \Gamma_{0}\right)>0$

ii) If $\Gamma_{E}<1$, then $\psi_{L}\left(\Gamma_{E}, \Gamma_{0}\right) \leq 0$ implies $\psi_{H}\left(\Gamma_{E}, \Gamma_{0}\right)<0$

iii) $\psi_{L}\left(\Gamma_{E}, \Gamma_{0}\right)=0$ implies $\psi_{H}\left(\Gamma_{E}, \Gamma_{0}\right)=\left(\Gamma_{E}-1\right) E\left[(1-\lambda) \frac{\Gamma_{H}}{\Gamma_{E}}\right]$, so that if $\Gamma_{E}=1, \psi_{H}\left(\Gamma_{E}, \Gamma_{0}\right)=0$

Proof of lemma 3: To show $i)$, notice that $\psi_{L}\left(\Gamma_{E}, \Gamma_{0}\right) \geq 0$ implies that

$$
\left(\Gamma_{E}-1\right) E \geq\left(\Gamma_{0}-\Gamma_{E}\right) w .
$$

Replacing $\left(\Gamma_{0}-\Gamma_{E}\right) w$ in $(25)$ we obtain:

$$
\begin{aligned}
\psi_{H}\left(\Gamma_{E}, \Gamma_{0}\right) \geq & \left(\Gamma_{E}-1\right) E\left[\lambda+(1-\lambda) \frac{\Gamma_{H}}{\Gamma_{E}}\right] \\
& -\lambda\left(\Gamma_{E}-1\right) E
\end{aligned}
$$

Rearranging and simplifying we have:

$$
\psi_{H}\left(\Gamma_{E}, \Gamma_{0}\right) \geq\left(\Gamma_{E}-1\right) E\left[(1-\lambda) \frac{\Gamma_{H}}{\Gamma_{E}}\right]
$$

The proof of $i$ ) and $i i i)$ is exactly the same.

We now proceed to prove proposition 3. Since there is a unique $\Gamma_{J}$ associated with any $\rho_{J}$ we can take $\Gamma_{J}$ to be the summary statistic for equity holders' beliefs.

We begin by showing that there are only three candidate equilibria:

- If $\psi_{L}\left(\Gamma_{E}, \Gamma_{0}\right)>0$ only a pooling equilibrium with $E=\bar{E}$ can exist. Suppose not and assume that instead $\psi_{H} \leq 0$. The consistency of equilibrium beliefs imply then $\Gamma_{0}=\Gamma_{H} \geq 0$, and $\Gamma_{E}=\Gamma_{L}$, so that $\Gamma_{0}-\Gamma_{E}>0$. Using (26) we obtain $\Gamma_{E}-1>0$. So that from lemma 3 , $\psi_{H}\left(\Gamma_{E}, \Gamma_{0}\right)>0$.which is a contradiction.

- Symmetrically, if $\psi_{L}\left(\Gamma_{E}, \Gamma_{0}\right)<0$ only a pooling equilibrium with $E=0$ can exist. Assume again by contradiction that $\psi_{H}\left(\Gamma_{E}, \Gamma_{0}\right) \geq 0$. Equilibrium beliefs then imply that $\Gamma_{E}=\Gamma_{H}$. But (26) then implies that $\Gamma_{E}<1$. As before, lemma 3 then yields a contradiction. 
- Finally, when $\psi_{L}\left(\Gamma_{E}, \Gamma_{0}\right)=0$ a mixed strategy equilibrium with $\Gamma_{E}=1$ is obtained where $\psi_{H}\left(\Gamma_{E}, \Gamma_{0}\right)=0$. To see why $\psi_{H}\left(\Gamma_{E}, \Gamma_{0}\right)=0$ in the semi-separating equilibrium, observe first that an equilibrium with $\psi_{H}\left(\Gamma_{E}, \Gamma_{0}\right)>0$ cannot exist. Indeed, when $\psi_{H}\left(\Gamma_{E}, \Gamma_{0}\right)>0$ equilibrium beliefs must be such that $\Gamma_{0}=\Gamma_{L}$ and $\left.i i i\right)$ of lemma 3 implies $\Gamma_{E}>1$

But then $\psi_{L}\left(\Gamma_{E}, \Gamma_{0}\right)=\left(\Gamma_{E}-1\right) E-\left(\Gamma_{0}-\Gamma_{E}\right) w>0$, a contradiction. Similarly when $\psi_{H}\left(\Gamma_{E}, \Gamma_{0}\right)<0$ equilibrium beliefs must be such that $\Gamma_{E}=\Gamma_{L}<0$. But then $\psi_{L}\left(\Gamma_{E}, \Gamma_{0}\right)=\left(\Gamma_{E}-1\right) E-\left(\Gamma_{0}-\Gamma_{E}\right) w<0$, again a contradiction because of $i$ ii $)$ of lemma 3 . Therefore, $\psi_{L}\left(\Gamma_{E}, \Gamma_{0}\right)=$ 0 implies both $\Gamma_{E}=1$ and $\psi_{H}\left(\Gamma_{E}, \Gamma_{0}\right)=0$.

We now show that any of the above candidate equilibria can exist. To do this we replace the equilibrium values for $\Gamma_{E}$ and $\Gamma_{0}$ in the functions $\psi_{H}$ and $\psi_{L}$. That is, for the pooling equilibrium with $E=0$ we have $\Gamma_{E}=\Gamma_{L}$, and for the pooling equilibrium with $E=\bar{E}$ we have $\Gamma_{0}=\Gamma_{L}$.

It is straightforward to show that equilibrium conditions for the pooling equilibrium with $E=0$ are satisfied when $\Gamma_{L}<1$, and that both pooling equilibria are met for a small enough $\Gamma_{L} \geq 1$, so that for the relevant range of parameters both of these equilibria do exist. Since $\Gamma_{H}>\Gamma_{L}$ a necessary condition for existence of a semi-separating equilibrium is that $\Gamma_{H}>1>\Gamma_{L}$. This establishes the first part of proposition 3 .

We now proceed to show that the cut-offs of the two pooling equilibria are ranked as follows: $\rho_{H}^{2}<\rho_{H}^{1}$.

Consider first the pooling equilibrium with $E=0$ and its cut-off $\rho_{H}^{1}$. We first observe that $\rho_{H}^{1}$ is the solution to the equation $\psi_{H}\left(\Gamma_{E}, \Gamma_{0}\right)=0$, or

$$
\begin{aligned}
\psi_{H}\left(\Gamma_{L}, \bar{\Gamma}\right)= & \left(\Gamma_{L}-1\right) \bar{E}\left[\lambda+(1-\lambda) \frac{\Gamma_{H}}{\Gamma_{L}}\right]- \\
& \lambda\left(\bar{\Gamma}-\Gamma_{L}\right) w=0
\end{aligned}
$$

To see this note that we must have $\Gamma_{L} \geq 1$ (and therefore $\Gamma_{E}>1$ ) at the cut-off, otherwise if $\Gamma_{L}<1$ both pooling equilibrium conditions for $E=0$ are satisfied strictly. But $\Gamma_{E}>1$ implies by lemma 3 that if $\psi_{L}\left(\Gamma_{E}, \Gamma_{0}\right)=0$ then $\psi_{H}\left(\Gamma_{E}, \Gamma_{0}\right)>0$.

Consider now the pooling equilibrium with $E=\bar{E}$. By similar reasoning the cut-off $\rho_{H}^{2}$ is the solution to the equation $\psi_{H}\left(\Gamma_{E}, \Gamma_{0}\right)=0$. Now, in the pooling equilibrium with $E=\bar{E}$ the function $\psi_{H}\left(\Gamma_{E}, \Gamma_{0}\right)$ is given by: 


$$
\begin{aligned}
\psi_{H}\left(\Gamma_{E}, \Gamma_{0}\right)= & (\bar{\Gamma}-1) \bar{E}\left[\lambda+(1-\lambda) \frac{\Gamma_{H}}{\bar{\Gamma}}\right]- \\
& \lambda\left(\Gamma_{L}-\bar{\Gamma}\right) w
\end{aligned}
$$

Subtracting equation (27) from (28) and rearranging we obtain:

$$
\psi_{H}\left(\Gamma_{E}, \Gamma_{0}\right)=\lambda\left(\bar{\Gamma}-\Gamma_{L}\right) E+(1-\lambda) E \pi_{H}\left(\frac{1}{\Gamma_{L}}-\frac{1}{\bar{\Gamma}}\right)-2 \lambda\left(\Gamma_{L}-\bar{\Gamma}\right) w
$$

so that $\psi_{H}\left(\Gamma_{E}, \Gamma_{0}\right)>0$ at the cut-off $\rho_{H}^{1}$. Finally, to show that the cut-off $\rho_{H}^{2}$ is below $\rho_{H}^{1}$ we prove that in the pooling equilibrium with $E=\bar{E}$ the function $\psi_{H}\left(\Gamma_{E}, \Gamma_{0}\right)$ is increasing in $\rho_{H}$.

To see this compute first the derivative $\frac{d \psi_{H}}{d \rho_{H}}$ using (28) and the fact that

$$
\frac{d \Gamma_{L}}{d \rho_{H}}=\frac{\hat{\nu}}{\kappa} \text { and } \frac{d \bar{\Gamma}}{d \rho_{H}}=\frac{1}{\kappa}\left(\frac{M}{M+m}+\frac{m}{M+m} \hat{\nu}\right)
$$

so that,

$$
\begin{aligned}
\frac{d \psi_{H}}{d \rho_{H}}= & \lambda E \frac{d \bar{\Gamma}}{d \rho_{H}}+(1-\lambda) E\left[\left(1-\frac{1}{\bar{\Gamma}}\right) \frac{d \Gamma_{H}}{d \rho_{H}}+\frac{\Gamma_{H}}{\bar{\Gamma}^{2}} \frac{d \bar{\Gamma}}{d \rho_{H}}\right] \\
& +\frac{\lambda}{\kappa}\left(\hat{\nu}-\left(\frac{M}{M+m}+\frac{m}{M+m} \hat{\nu}\right) w\right.
\end{aligned}
$$

Since in the pooling equilibrium with $E=\bar{E}$ we have $\bar{\Gamma}>1$ the above expression is the sum of three positive terms so that the function $\psi_{H}\left(\Gamma_{E}, \Gamma_{0}\right)$ is increasing in $\rho_{H}$.

Note that this argument also establishes that a pooling equilibrium with $E=\bar{E}$ exists in a neighborhood of the limiting point $\rho_{H}^{1}$ so that there are multiple pooling equilibria in a neighborhood of $\rho_{H}^{1}$.

\section{References}

[1] Bernanke, B.S. and C.S. Lown (1991) "The Credit Crunch", Brooking Papers on Economic Activity, pp. 204-239. 
[2] Bernanke, B.S. and M. Gertler (1995) "Inside the Black Box: the Credit Channel of Monetary Policy Transmission", New York University Working Paper.

[3] Bernanke B.S. and M.Gertler (1990) "Financial Fragility and Economic Performance", Quarterly Journal of Economics, 105(1), 87-114

[4] Bolton, P. and X.Freixas (2000) "Equity, Bonds and Bank Debt: Capital Structure and Financial Market Equilibrium under Asymmetric Information", forthcoming Journal of Political Economy

[5] Cecchetti, S. (1999) "Legal Structure, Financial Structure and the Monetary Transmission Mechanism" NBER Working Paper 7151

[6] Cho, I. K. and D. M. Kreps (1987) "Signalling games and stable equilibria" , Quarterly Journal of Economics , 102, pp.179-221

[7] Dybvig, P. and Zender, J. (1991) "Capital Structure and Dividend Irrelevance with Asymmetric Information", Review of Financial Studies 4, pp.201-19.

[8] Gale, D. (1993) , "Informational Capacity and Financial Collapse" in C.Mayer and X.Vives, eds. Capital markets and financial intermediation.. Cambridge; New York and Melbourne: Cambridge University Press, pages 117-48.

[9] Gertler, M. and S. Gilchrist (1993) "The Role of Credit Market Imperfections in the Monetary Transmission Mechanism: Arguments and Evidence", Scandinavian Journal of Economics, 95, 43-64

[10] Gertler, M. and S. Gilchrist (1994) "Monetary Policy, Business Cycles, and the Behavior of Small Manufacturing Firms", Quarterly Journal of Economics 109, May, pp. 309-40.

[11] Gilson, S.K.J. and L. Lang (1990) "Troubled Debt Restructurings: an Empirical Study of Private Reorganization of Firms in Default", Journal of Financial Economics 27, pp. 315-53.

[12] Gorton, G. and A.Winton (1999) "Liquidity Provision, the Cost of Bank Capital, and the Macroeconomy", mimeo, University of Minesota 
[13] Holmstrom, B. and J. Tirole (1997) "Financial Intermediation, Loanable Funds and the Real Sector" Quarterly Journal of Economics, 112, 663691

[14] Hoshi, T., Kashyap, A., and D. Scharfstein (1993) "The Choice between Public and Private Debt: an Analysis of Post-Deregulation Corporate Financing in Japan" mimeo, MIT.

[15] Kashyap, A., Stein, J.C., and D.W. Wilcox (1993) "Monetary Policy and Credit Conditions: Evidence from the Composition of External Finance", American Economic Review 83, pp. 78-98.

[16] Kashyap, A. and J.C. Stein (1994) "Monetary Policy and Bank Lending", in N. Gregory Mankiw, ed. Monetary Policy, University of Chicago Press for National Bureau of Economic Research.

[17] Lummer, S. and J. McConnel (1989) "Further Evidence on the Bank Lending Process and the Reaction of the Capital Market to Bank Loan Agreements", Journal of Financial Economics 25, pp. 99-122.

[18] Myers, S.C. and N.S. Majluf (1984) "Corporate Financing and Investment Decisions when Firms have Information that Investors do not have", Journal of Financial Economics 13, pp. 187-221.

[19] Oliner, S. and G. Rudebush (1994) "Is there a Broad Credit Channel?" Board of Governors, mimeo.

[20] Petersen, M. and R. Rajan (1994) "The Benefits of Lending Relationships: Evidence from Small Business Data", Journal of Finance, 49, March, pp. 3-37.

[21] Petersen, M. and R. Rajan (1995) "The Effect of Credit Market Competition on Lending Relationships", Quarterly Journal of Economics, 110, May, pp. 407-43.

[22] Repullo, R. and J. Suarez (1998) "Entrepreneurial Moral Hazard and Bank Monitoring: a Model of The Credit Channel", forthcoming, European Economic Review.

[23] Romer, C. and D. Romer (1990) "New Evidence on the Monetary Transmission Mechanism", Brookings Papers on Economic Activity, No 1, $149-213$ 
[24] Schneider, M. (1998) "Borrowing Constraints in a Dynamic Model of Bank Asset and Liability Management", mimeo, Stanford University

[25] Stein, J. (1998) "An Adverse-Selection Model of Bank Asset and Liability Management with Implications for the Transmission of Monetary Policy" Rand Journal of Economics, 29, No 3, 466-87

[26] Thakor, A. (1996) "Capital Requirements, Monetary Policy, and Aggregate Bank Lending: Theory and Empirical Evidence", Journal of Finance, 51

[27] Van den Heuvel, S. (1999) "The Bank Capital Channel of Monetary Policy", mimeo, Yale University 